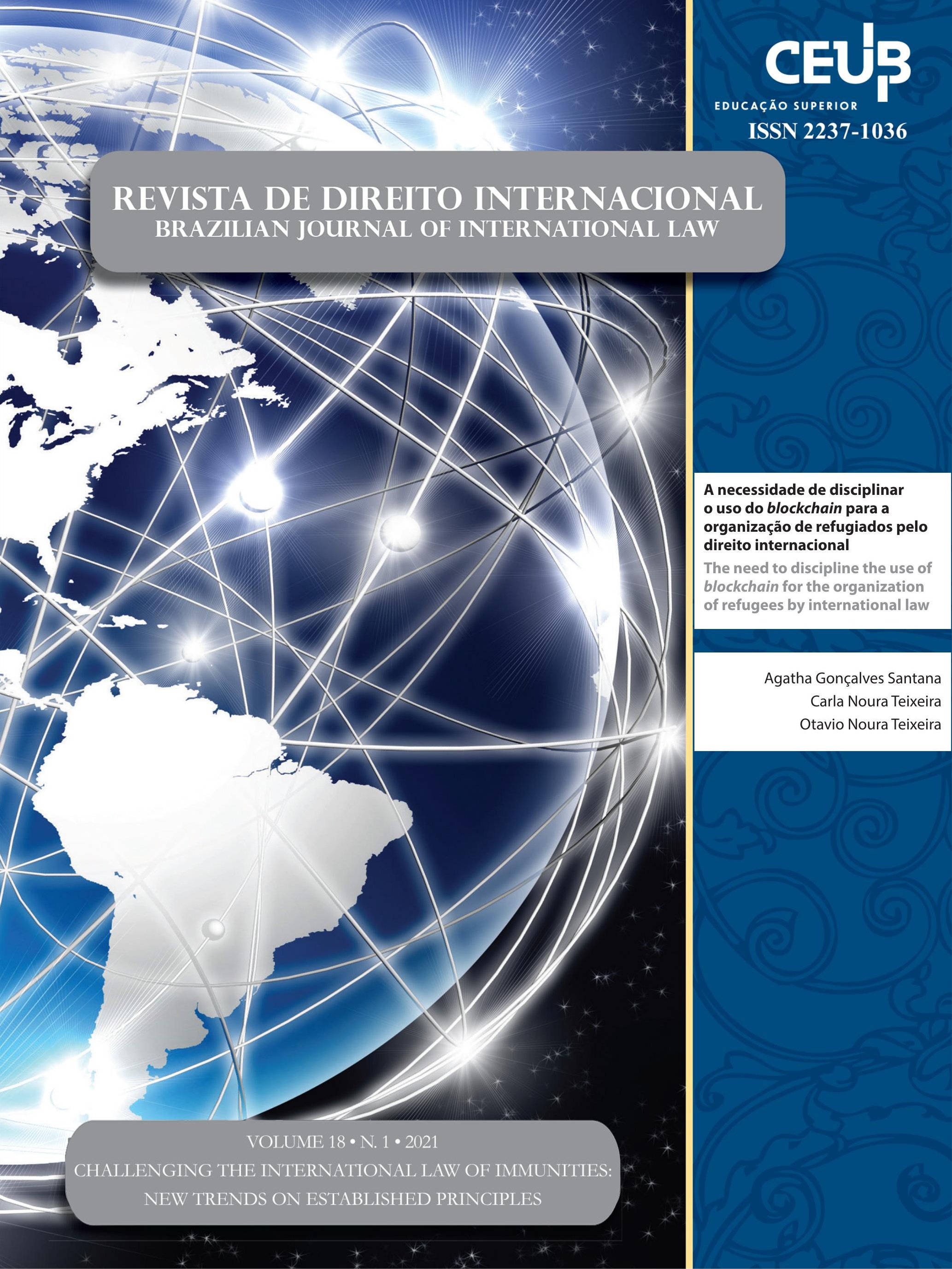


EDITORIAL

Challenging the International Law of Immunities: New Trends on Established Principles? An introduction to the special issue ............................................ 14

Lucas Carlos Lima, Loris Marotti e Paolo Palchetti

CrôniCAS........................................................................................ 17

RESPONSABILIDADE E IMUNIDADE DAS ORgANIZAÇÕES INTERNACIONAIS: PRÁTICA E DESAFIOS ...19 Vinícius Fox Drummond Cançado Trindade

The JURISDiCTIONAL IMMUNITY OF INTERNATIONAL ORgaNiZATIONS BEFORE THE BRAZILIAN SuPREMe Federal Court.

Bárbara Tuyama Sollero

The Law of State Immunity before the Brazilian Supreme Court: what is at stake WITH THE "ChANGRI-LA" CASE?

Aziz Tuffi Saliba e Lucas Carlos Lima

\section{Dossiê: Challenging the International Law of Immunities: New Trends} on Established Principles?

State Immunity and the Rights of Employees: Lights and Shadows of the Strasbourg COURT's JURISPRUdENCE .61

Pierfrancesco Rossi

A human Rights-BASEd CHALlENGE: THE KEY TO UNLOCK THE UN'S IMMUNiTY PROBLEM?...79 Héloïse Guichardaz

IMMUNITIES OF STATE OFFICIALS AND THE "FUNDAMENTALLY DIFFERENT NATURE" OF INTERNATIONAL COURTS: THE APPEALS CHAMBER DECISION IN THE JORDAN REFERRAL RE AL BASHIR ...97 Rita Guerreiro Teixeira e Hannes Verheyden 
IMUNIDADE DE JURISDIÇÃo dOS EsTADOS: O CAMINHO PARA A RELATIVIZAÇÃo

Vinícius Assis da Silveira, Luiz Felipe Costa Santana e Valesca Raizer Borges Moschen

The IMmUNity OF INTERNATIONAL ORganizations IN LABOUR DispUTES. DeVElopments BEFORE INTERNATIONAL TRIBUNALS, NATIONAL COURTS AND THE COLOMBIAN JURISDICTION ..... 137 Walter Arévalo-Ramirez e Ricardo Abello-Galvis

Imunidade de Jurisdição dos Estados E Poder Executivo brasileiro: os Pareceres dos CONSULTORES JURÍDICOS DO ITAMARATY

George Rodrigo Bandeira Galindo

Artigos SOBRe outros temas

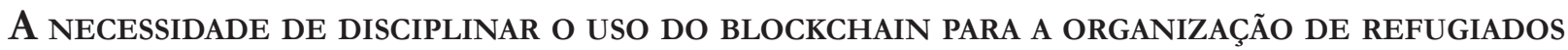
PELO DIREITO INTERNACIONAL. 195

Agatha Gonçalves Santana, Carla Noura Teixeira e Otavio Noura Teixeira

O TRABALHO INFANTIL DE MIGRANTES E REFUgIADOS VENEZUELANOS NO BRASIL

André Viana Custódio e ohana Cabral

THE NEW BRAZILIAN ANTI-TRAFFICKING LAW: CHALLENGES AND OPPORTUNITIES TO COVER THE NORMATIVE LACK . 243 Waldimeiry Correa da Silva

¿SON PARTE DEL BLOQUE DE CONSTITUCIONALIDAD LOS TRATADOS INTERNACIONALES DE DERECHOS HuMANOS DE LA OEA EN CHILE?: AVANCES EN BASE A LA DOCTRINA, NORMATIVA Y JURISPRUDÊNCIA. 270

Juan Pablo Díaz Fuenzalida

O Tratado de Saint-Germain-En-Laye e os Efeitos do instituto da “opÇão” Sobre a CONDIÇÃO JURÍDICA DOS DESCENDENTES DE CIDADÃOS AUSTRÍACOS TRENTINO-TIROLÊSES ......290 Arno Dal Ri Jr. e Andrey José Taffner Fraga

Control Judicial de la Corte Interamericana de Derechos Humanos y Programas Masivos de Reparaciones: Hacia un Enfoque más Matizado .309 Juan Carlos Ochoa-Sánchez 
JuSTICIABILIDADE DIRETA DOS DIREITOS ECONÔMICOS, SOCIAIS, CULTURAIS E AMBIENTAIS NA

Corte Interamericana DE Direitos Humanos..........................................................334

Augusto Antônio Fontanive Leal e Guilherme Massaú

How the indigenous case of Xukuru before the Inter-American Court of Human RiGHTS CAN INSPIRE DECOLONIAL COMPARATIVE STUDIES ON PROPERTY RIGHTS..........................353

Flavianne Fernanda Bitencourt Nóbrega e Camilla Montanha 


\title{
A necessidade de disciplinar o uso do blockchain para a organização de refugiados pelo direito internacional*
}

\author{
The need to discipline the use of blockchain \\ for the organization of refugees by \\ international law
}

\author{
Agatha Gonçalves Santana** \\ Carla Noura Teixeira*** \\ Otavio Noura Teixeira****
}

* Recebido em 23/04/2020

Aprovado em 01/05/2021

** Doutora (2017) e Mestre (2009) em Direito pela Universidade Federal do Pará - UFPa. Professora titular de Teoria Geral do Processo e Direito Processual Civil da Universidade da Amazônia. Líder do Grupo de Ensino e Pesquisa acerca das Teorias Gerais do Processo - O Processo como instrumento de realização dos Direitos Fundamentais da Universidade da Amazônia - CNPq. Advogada. Email: agathadcpc@yahoo.com.br

*** Doutora em Direito do Estado pela Pontifícia Universidade Católica de São Paulo (2009) e Mestre em Direito das Relações Sociais pela Pontifícia Universidade Católica de São Paulo (2003). Especialista em Direito Processual (2000). Coordenadora e Professora do Programa de Pós Graduação Stricto Sensu Mestrado em Direitos Fundamentais da Universidade da Amazônia - UNAMA. Professora da Graduação em Direito da Universidade da Amazônia - UNAMA, da UNIFAMAZ e da UNINASSAU. Membro do Instituto Brasileiro de Direito Constitucional - IBDC.

E-mail: c.noura@uol.com.br

**** Professor Adjunto da Universidade Federal do Pará (UFPA) - Campus Tucuruí (CAMTUP). Doutor e Mestre em Engenharia Elétrica, na área de Computação Aplicada, pela Universidade Federal do Pará. Atualmente é Diretor da Faculdade de Engenharia de Computação, membro do Conselho Deliberativo do CAMTUC, membro permanente do Programa de Pós-Graduação em Computação Aplicada (PPCA) e, professor orientador e supervisor, área de Computação, da Empresa Junior "Esquadro Projetos e Consultorias", do CAMTUC-UFPA.

E-mail: o.noura@gmail.com

\section{Resumo}

A partir da experiência do uso da tecnologia disruptiva do blockchain como forma de identificação de refugiados sírios na Jordânia pela ONU a partir de 2017, como parte de um projeto piloto do Programa Mundial de Alimentos - PMA, demonstra-se, neste artigo, a necessidade da disciplina dessa tecnologia pelo direito, a partir da introdução de seus conceitos operacionais básicos, além da apresentação do direito internacional na perspectiva dos direitos humanos em relação à proteção da pessoa do refugiado. Apresentase as vantagens e desvantagens práticas de seu uso, com base na observação não apenas da experiência realizada como também sobre as viabilidades que poderão ser aplicadas ao futuro, as quais terão de enfrentar análises das implicações éticas e jurídicas, tendo como baliza do Direito Internacional dos Refugiados. A pesquisa, inicialmente teórica, é intercalada com a análise de dados empíricos, predominando uma abordagem qualitativa de lógica dialético-indutiva em uma visão fenomenológica pela possibilidade de expansão do uso dessa tecnologia para efeitos de registros para refugiados em todo o mundo a partir dessa experiência. Com base nessas premissas, devem-se considerar os benefícios bem como os altos riscos de violação dos direitos dessas pessoas em situação de sobreposição de vulnerabilidades com a aplicação em larga escala dessa tecnologia, concluindo-se pela criação de guidelines ou balizas interpretativas à luz dos fundamentos e princípios do sistema de Direito Internacional do Refugiado, de modo a reduzir a sobreposição de vulnerabilidades em que se encontram.

Palavras-chave: Refugiados; Direito Internacional dos Refugiados; Blockchain; Sobreposição de vulnerabilidades.

\section{Abstract}

Based on the experience of using the disruptive technology of blockchain as a way of identifying Syrian refugees in Jordan by the UN from 2017, as part of a pilot project of the World Food Program - WFP, this article aims to 
demonstrate the need for discipline of this technology by law, from the introduction of its basic operational concepts, in addition to the presentation of international law from the perspective of human rights in relation to the protection of the refugee person, presenting the practical advantages and disadvantages of its use, from the observation not only of the experience carried out but also of the feasibility that may be applied to the future, which will have to face analyzes of the ethical and legal implications, having as a guideline of International Refugee Law. The research, initially theoretical, is interspersed with empirical research, predominantly a qualitative approach of dialectic-inductive logic in a phenomenological view due to the possibility of expanding the use of this technology for the purposes of registering for refugees worldwide from this experience. Based on these premises, one should consider the benefits as well as the high risks of violating the rights of these hypervulnerable people with the large-scale application of this technology, concluding with the creation of guidelines or interpretive guidelines in the light of the fundamentals and principles of the system. International Refugee Law, in order to reduce the overlap of vulnerabilities in which they find themselves.

Keywords: Refugees; international refugee law; Blockchain; dignity of the human person.

\section{Introdução}

Oriundo do contexto tecnocapitalista planetário observado nas últimas décadas, a tecnologia blockchain foi idealizada por Stuart Haber e W. Scott Stornetta no início dos anos 90, inicialmente envolvendo a criação de uma rede de blocos de documentos protegidos criptograficamente, não podendo serem alterados seus registros de data e hora. Essa tecnologia foi desenvolvida posteriormente, após mais de uma década, por uma pessoa, ou grupo de pessoas, cujo pseudônimo ficou conhecido como Satoshi Nakamoto, criando, por meio desse aperfeiçoamento, a criptomoeda mais difundida mundialmente, o Bitcoin ${ }^{1}$.

${ }^{1}$ LAMOUNIER, Lucas. A bistória da tecnologia Blockechain: conheça sua Timeline. 101Blockchains, 2018. Disponível em: https://101blockchains.com/pt/historia-da-tecnologia-blockchain/. Acesso em: 22 abr. 2021.
De modo geral, blockchain é uma espécie de tecnologia de registro de contabilidade distribuída, como um livro-razão. Trata-se de um sistema digital no qual os dados são registrados em vários locais concomitantemente, diferentemente dos bancos de dados tradicionais, pois não há um administrador central ou uma centralização no armazenamento de dados, automaticamente replicados em "blocos" ou "cadeias". Assim, essa característica garantiria uma segurança maior, dado não ser possível excluir ou modificar informações na cadeia de dados armazenados ${ }^{2}$.

Assim, embasa-se em uma arquitetura de computadores ou redes que compartilham arquivos de dados entre si, distribuindo tais dados de modo descentralizado, usando por meio programas ou algoritmos que auxiliem a gestão desses dados. O blockchain, dessa forma, uma vez que possui sua informação encriptada, torna-se um ambiente privado, não havendo como rastrear quem adicionou a informação na rede, mas somente verificar se tal adição é válida.

Principalmente associada a criptomoedas, devido à incapacidade de adulterar as transações e rastrear fragmentos de dados registrados, seus defensores alegam que isso torna essa tecnologia mais segura e protegida do que os sistemas mais tradicionais.

As plataformas de blockchain podem oferecer outras possibilidades, como contratos inteligentes ou smart contracts, implementados automaticamente, reduzindo o tempo envolvido e o risco de erros; para fins de armazenamento de registros médicos, para que pacientes possam ter certeza de que suas informações não sejam alteradas; eleições; ou utilizada para armazenar registros de propriedades.

O uso dessa tecnologia ignora a necessidade de um provedor financeiro, como um banco, reduzindo assim os custos em até $98 \%$, um dos motivos pensados para sua aplicação na conhecida experiência dos refugiados sírios na região da Jordânia a partir do ano de 2017, quando a ONU passa a utilizar o chamado building blocks, em auxilio ao Programa Mundial de Alimentos - PMA por meio da utilização de tecnologias como o blockchain, inicialmente utilizado como forma de economia, com o objetivo de reduzir taxas e evitar tentativas de fraudes e corrupção ${ }^{3}$.

\footnotetext{
2 TAPSCOTT, Don; TAPSCOTT, Alex. Blockchain Revolution. São Paulo: SENAI-SP, 2016. p. 3-39.

3 THE NATIONAL FUTURE. How blockchain technology has changed
} 
A versão atual do Building Blocks, utilizadas na Jordânia em relação aos refugiados sírios, é executada em uma versão privada ou autorizada do Ethereum, em que uma autoridade central decide quem pode participar. A vantagem desse sistema de permissão é a possibilidade de processamento das transações com mais rapidez e menor custo. A desvantagem refere-se a como o PMA controla quem entra na sua própria rede, também detém o poder de reescrever históricos de transações, o que pode causar certa instabilidade em relação à segurança ${ }^{4}$.

Graças às informações obtidas em tempo real, os atendentes de chamadas na central direcionada ao cliente podem executar tarefas como responder consultas, desbloquear contas e autorizar transações em poucos minutos, ao invés de semanas, dispensando-se o uso de cupons ou vales de papel. Informações tais como nome e data de nascimento não são visíveis para aqueles que acessam o sistema, apenas podendo visualizar o número de identificação de determinada pessoa e os benefícios aos quais têm direito.

Idealizado com base na necessidade de economizar gastos por meio do uso da Building Blocks, a organização passou da distribuição de produtos alimentícios para a transferência de dinheiro para pessoas que precisam adquirir alimentos. Essa abordagem tem por escopo alimentar mais pessoas, ao mesmo tempo que tenta melhorar as economias locais e aumentar a transparência.

Afinal, porque o direito internacional deve intervir, disciplinando o uso da tecnologia blockchain, a qual se mostra tão promissora e eficiente, cumprindo seu papel de ajuda às pessoas refugiadas?

Os objetivos essenciais deste artigo são: i) realçar os pontos de vantagens e desvantagens práticas do uso da tecnologia para fins de organização de refugiados, ou mesmo, futuramente, para conservação plena de dados que conservem elementos pessoais referentes à preservação de sua ancestralidade antropológica e cultura de origem; bem como ii) a necessidade da interpretação do

the game for Syrian refugees in Jordan. Abu Dhabi, 2019. Disponível em: https://www.thenational.ae/arts-culture/how-blockchain-technology-has-changed-the-game-for-syrian-refugees-in-jordan-1.932432. Acesso em: 22 abr. 2021.

4 JUSKALIAN, Russ. Inside the Jordan refugee camp that runs on blockchain. Massachussets: Mit Technology Review, May/Jun. 2018. Disponível em: https://www.technologyreview.com/s/610806/ inside-the-jordan-refugee-camp-that-runs-on-blockchain/. Acesso em: 22 abr. 2021. uso dessa tecnologia à luz do Direito Internacional dos Refugiados, devendo-se garantir os princípios do humanismo ético que permeia os direitos humanos mais básicos dessas pessoas, sendo necessária uma análise sistemática sobre os direitos conquistados a partir da Convenção de Genebra em 1951, conhecida como o "Estatuto dos refugiados".

Muitos pontos devem ser levantados sobre as lacunas ainda existentes, de modo a garantir em plenitude a dignidade dessas pessoas com base no uso dessa tecnologia que, destaque-se primeiramente, utiliza todos os dados de um ser humano.

Isso porque a problemática se assenta em um paradoxo: se por um lado ela pode ser benéfica e promover direitos dos refugiados, por outro ainda restam dúvidas sobre quem lança e como são lançados esses dados, bem como quais os critérios de lançamento, levanta a possibilidade da utilização desses dados com fins enviesados para um controle exacerbado. E ainda que essa tecnologia seja considerada, em uma situação ideal, totalmente privada ou blindada de possíveis interferências externas, poderia ocasionar utilização para fins ilícitos, prejudicando os direitos dos refugiados, tal qual a inserção de informações fraudulentas para fins de entrada e permanência irregular, ou seja, sem preencher os requisitos legais de fato para a concessão de refúgio a pessoas que de fato dele necessitam.

Assim, considera-se o fenômeno tecnológico como um evento que deve não apenas ser analisado cientificamente, mas também refletido para que os direitos humanos sejam efetivados, essencialmente sobre populações hipervulneráveis, como é o caso dos refugiados, assim definidos pela Convenção de Genebra como toda pessoa que teme ser perseguida por motivos de raça, religião, nacionalidade ou opiniões políticas - elementos não apenas inerentes ao projeto de vida do indivíduo, mas à sua própria essência desde o início de sua existência - em seu próprio país de origem, que peça refúgio para outro país.

Com efeito, a justificativa da problemática e a preocupação central dos escopos da investigação é a efetividade do Direito Internacional dos Refugiados ${ }^{5}$, que procura não apenas reconhecer como garantir as necessidades existenciais mais básicas daqueles que se veem

5 PIOVESAN. Flávia Cristina; OLSEN, Ana Carolina Lopes. Tolerância e refúgio: Um ensaio a partir do acordo EU-Turquia. Revista de Direito Internacional, Brasília, v. 14, n. 2, 2017. p. 218. 
obrigados a deixar seu país por um grave e compreensível receio, com o direito de solicitar asilo, o que se tornou preocupação mundial após os intensos deslocamentos de pessoas provocados pelas grandes guerras mundiais. Estas não poderiam ser vistas eticamente como objetos, mas sim como sujeitos de direito.

Paradoxalmente, pontua-se como a tecnologia tem aptidão tanto para ampliar como para reduzir o conceito de pessoa, uma vez que a privacidade e a identidade se interligam na esfera digital, dado que a rede mundial de computadores passa a interagir com a biografia de um indivíduo, o que poderá fazê-lo em múltiplas versões, correndo-se o risco de perder-se a identidade para a rede de dados ${ }^{6}$.

Além disso, também se destaca a dúvida sobre ética da utilização dessa tecnologia, em relação à realização de experiências com refugiados, que merecem maior proteção dada sua condição de hipervulnerabilidade, uma vez que a coleta maciça de informações e de identificação por meios análogos à biometria tem sido historicamente grande problema para as pessoas em situação de migração.

Dessa forma, tais informações podem ser utilizadas para fins discriminatórios e violações às convenções e tratados internacionais, como por meio da utilização de seus dados para a formação de políticas "crimigratórias", termo salientado por Santos e Brasil", da utilização de dados obtidos por meio dessa tecnologia, a fim de justificar o endurecimento de políticas para desestimular possíveis entradas clandestinas, concedendo tratamento mais severo, aplicando exacerbada vigilância, interceptações, deportações e detenções, tendo como frágil argumento a segurança, transformando dificuldades estruturais em culpabilização de indivíduos.

Isso porque os Estados hospedeiros não raras vezes desconsideram as especificidades de cada povo, podendo causar, inclusive, uma erosão cultural $^{8}$, ou mesmo

\footnotetext{
${ }^{6}$ RODOTÀ, Stefano. Dal soggetto alla persona. Napoli: Editoriale Scientífica, 2007. p. 53-59.

7 SANTOS, Regina Cândido Lima e Silva; BRASIL, Deilton Ribeiro. O tipo penal brasileiro de promoção de migração ilegal e o princípio da não criminalização da mobilidade humana. Revista de Direito Internacional, Brasília, v.17, n. 2, p. 337, 2020.

8 FIGUEIRA, Rickson Rios. Indigenous refugee and cultural erosion: possibilities and limits of international refugee and indigenous peoples law in the protection of indigenous cultural expression related to traditional land and traditional native languages. Revista de Direito Internacional, Brasília, v. 17, n. 3., p. 447-448, 2020.
}

quando países hospedeiros têem seus níveis de tolerância e solidariedade são colocados à prova, abrindo espaço para racismo e discriminação?.

Esse contexto, portanto, faz com que se sugira uma disciplina específica para o uso dessa tecnologia aos refugiados no âmbito do direito internacional, não para suprimi-la, dado o seu grande potencial de utilização para uma série de benefícios inclusive para a promoção da vida digna dessas pessoas, por outro lado sempre com os limites estabelecidos.

Dessa forma, em relação à metodologia utilizada, justificam-se abaixo as abordagens, métodos e técnicas utilizadas para a consecução dos fins aos quais esse trabalho se propõe, utilizando-se alternadamente, as metodologias documentais de caráter teórico, bem como de bases empíricas.

Dividido em três partes, o presente artigo possui etapas metodológicas específicas, partindo-se da pesquisa predominantemente teórica, com elementos de empiria coletados essencialmente sobre o estudo de caso da experimentação do uso da tecnologia blockchain sobre os refugiados da Síria a partir do ano de 2017.

$\mathrm{Na}$ primeira parte da pesquisa, destaca-se a importância do uso da tecnologia blockchain pelo direito internacional, essencialmente quando da sua utilização em relação a populações hipervulneráveis, como é o caso dos refugiados. Com base em uma abordagem quanti-qualitativa, a natureza metodológica, neste primeiro momento, é básica de objetivo exploratório, dada a análise geral acerca da necessidade de discussão sobre aplicações e limites dessa tecnologia. Procedeu-se com o levantamento bibliográfico-documental, essencialmente confrontando os valores éticos do uso da tecnologia a serem considerados, em relação às possibilidades de aplicação sobre populações hipervulneráveis, como no caso dos refugiados, o que justifica um primeiro debate e disciplina por parte do direito internacional. A lógica que predomina neste primeiro momento é a hipotético-dedutiva, para a construção de hipóteses a serem consideradas pelo Direito Internacional.

Na segunda etapa ou parte da pesquisa, com enfoque maior na pesquisa empírica, essencialmente utilizou-se do procedimento do estudo de caso. Assentada em uma

\footnotetext{
9 PIOVESAN. Flávia Cristina. OLSEN, Ana Carolina Lopes. Tolerância e refúgio: Um ensaio a partir do acordo EU-Turquia. Revista de Direito Internacional, Brasília, v. 14, n. 2, 2017. p. 221.
} 
abordagem qualitativa, a pesquisa toma contornos de natureza aplicada e objetivos descritivos para que se possa realizar a análise crítica posterior, predominando a lógica indutiva nesta ocasião. Nessa ocasião, há uma observação fenomenológica interpretativista, com base na análise do caso observado, bem como na descrição, compreensão e interpretação dos fenômenos de aplicação do uso da tecnologia sob um olhar transdisciplinar e transversal. Descreve-se as variáveis e suas incidências com base na análise longitudinal do caso específico da experiência do uso blockchain pelos refugiados sírios da Jordânia.

A partir desse ponto, os dados serão submetidos à metanálise e, posteriormente, confrontados com a experiência do uso da tecnologia pela ONU na Jordânia em relação aos refugiados sírios. Nesse sentido, será aplicado o critério lógico de análise indutivo.

Desta forma, para que se possa ressaltar a tese central, apresenta-se o assim denominado "Direito Internacional dos Refugiados" como guia interpretativo, para a criação de guidelines relativa ao uso do blockchain a essas populações hipervulneráveis, como supressão da sobreposição da vulnerabilidade, retornando aos métodos de abordagem quantitativa de natureza aplicada, de objetivo prescritivo no sentido de sugerir uma interpretação específica à luz dos princípios normativos que permeiam os direitos dos refugiados para a garantia da efetivação de sua dignidade e de uma vida digna nesse momento de virada tecnológica do direito ocorrida mundialmente, respeitando-se as origens, cultura, idioma, liberdade e a garantia de todos os interesses juridicamente tutelados para que os refugiados possam retomar seus projetos de vida, já desviados por guerras ou outros motivos que os fizeram abruptamente requerer refúgio em outro país.

\section{2 importância da disciplina do uso do blockchain pelo Direito Internacional: a particularidade sobre o direito dos refugiados.}

Paralelamente ao fenômeno da globalização, o desenvolvimento tecnológico das últimas décadas caracteriza um outro fenômeno mundial a ser observado com cuidado de descobrir suas estruturas existenciais bem como as entidades que lhes correspondam, de modo a ganhar contornos de questionabilidade ${ }^{10}$ ao que se denomina de "tecnoglobalização".

Conceitos como ética, justiça e dignidade são preceitos tradicionais universais, que não podem jamais ser superados, embora modificados em suas leituras ao longo das mudanças sociais e, hodiernamente, pelo desenvolvimento tecnológico.

Destarte, haverá sempre um espaço para questionamento das ações humanas, que ultrapassam o mero alcance dos resultados cogitados ou pretendidos. E, nas palavras de Rosas"11, "no âmbito do desenvolvimento tecnológico, observa-se um aparente distanciamento ético e humano, desde a concepção de uma ideia aos primeiros passos em direção à sua realização, "causado pela diminuição do contato direito entre as pessoas e pela facilidade de anonimização", essencialmente pela criação de frameworks e realidades fictícias interativas ou mesmo pela ação da inteligência artificial, devendo-se sempre alertar a importância da ética e da dignidade dentro e fora do ambiente digital.

$\mathrm{Na}$ realidade, deve-se garantir que todas as vitórias sobre a humanização do direito conquistadas ao longo dos séculos não sofram certo grau de erosão quando parte da atenção dispensada ao sujeito de direito volta-se para o objeto, como no caso as tecnologias desenvolvidas nas últimas décadas.

A tecnologia enquanto fenômeno possui ritmo muito mais veloz do que a filosofia, a sociologia, o direito ou a política. Aquela possui um caráter muito mais cartesiano, radical, taxativo e final do que estas.

Destaque-se que, a tecnologia, de um modo geral, limita ajustes nas soluções de conflitos de acordo com expectativas sociais ou dos casos concretos, ou seja, a casuística. No ciberespaço são evidenciados o determinismo, a binariedade, a arquitetura de simplicidade e a privacidade como expressão de liberdade ${ }^{12}$.

\footnotetext{
10 HUSSERL, Edmund. A ideia da fenomenologia. Lisboa: Edições 70, 1989. p. 53.

11 ROSAS, Eduarda Chacon. Alcance resultados, mas não se esqueça dos propósitos: a dignidade, a ética e os elevados fins. In: MALDONALDO, Viviane Nóbrega; FEIGELSON, Bruno. Advocacia 4.0. São Paulo: Revista dos Tribunais, 2019. p. 201.

12 KARAVAS, Vaios; TEUBNER, Gunther. The Horizontal Effect of Fundamental Rights on Private Parties' within Autonomous Internet Law. Cambridge: Cambridge Press University, 2002. Disponível em: https://www.cambridge.org/core/services/aop-cambridge-core/ content/view/6195520133A79D7A577B9AFCFC383BB3/ S2071832200012153a.pdf/httpwwwcompanynamesuckscom_the horizontal_effect_of_fundamental_rights_on_private_parties_
} 
No artigo primeiro da Declaração Universal dos Direitos Humanos - DUDH ${ }^{13}$, já se extraem muitos princípios essenciais, tais como liberdade, igualdade e dignidade. Muito além de uma carga axiológica, consagram valores e finalidades a serem realizadas.

Nesse sentido, nas palavras de Piovesan ${ }^{14}$, a concepção internacional dos direitos humanos contemporânea é aquela pela qual são eles uma "unidade indivisível, interdependente e interrelacionada, na qual os valores da igualdade e liberdade se conjugam e se completam". Necessariamente, deve-se ter em foco uma compreensão da sistemática internacional de proteção dos direitos humanos em relação ao exame de seus aparatos de proteção aos direitos humanos.

Dessa forma, trata-se de um direito cuja essência tem caráter protetivo, garantidor dos bens mais básicos à existência humana, marcado com uma lógica própria, voltado à proteção dos seres humanos, não do Estado ou demais pessoas jurídicas, as quais, muitas vezes, podem causar danos maiores que o próprio poder público, face ao agigantamento do poder privado da atualidade ${ }^{15}$. Não rege, portanto, a relação entre sujeitos em igualdade, mas sim em situação de vulnerabilidade, almejando diminuir os efeitos dos desequilíbrios das relações de poder e das disparidades delas originadas.

A lógica, assim utilizada, é de uma ética existencial, de caráter transcendente em sua essência, não sendo deduzido de uma lógica meramente cartesiana ou matemática, o que significa dizer que ainda que uma inovação disruptiva possa parecer, em um primeiro momento, operacional e, numericamente, efetiva em relação ao grau de eficiência da produção ou produtividade extraída das relações entabuladas, não poderá jamais violar o conteúdo dos direitos da personalidade humana, que lhe confere seu caráter existencial.

Assim, em um contexto tecnológico cuja velocidade se exceda à análise ética, sociológica e jurídica, há de

within_autonomous_internet_law.pdf. Acesso em: 22 abr. 2021.

13 DECLARAÇÃO UNIVERSAL DOS DIREITOS HUMANOS. Assembleia Geral das Nações Unidas em Paris. 10 dez. 1948. Disponível em: https://nacoesunidas.org/wp-content/uploads/2018/10/ DUDH.pdf Acesso em: 22 abr. 2021.

14 PIOVESAN, Flávia. Direitos Humanos e o Direito Constitucional Internacional. 14. ed. São Paulo: Saraiva, 2013. p. 75.

15 SANTANA, Agatha Gonçalves. Os direitos fundamentais como limite ao poder privado. (Dissertação de mestrado). Belém: UFPa, 2009. p. 12. Disponível em: http://repositorio.ufpa.br/jspui/bitstream/2011/6750/1/Dissertacao_TutelaDireitosFundamentais. pdf. Acesso em: 22 abr. 2021. se preocupar com a realização das finalidades expressas nas normas do caput do artigo primeiro da DUDH. Isso porque as novas gerações estão já sendo tecno-alfabetizadas desde os primeiros meses de vida, bem como há um movimento de inserção quase que forçada dos mais velhos às novidades digitais. Conforme lembrado por Rosas ${ }^{16}$, "Os reflexos individuais ou sociais dessas transformações ainda estão por serem completamente conhecidos e estão longe de serem adequadamente avaliados".

A tendência da novidade é a ausência de tempo para imposição de limites, tendendo-se a observar a ocorrência de abusos, o que potencializa a possibilidade de conversão, com o tempo, em ilicitude ${ }^{17}$, devendo-se ter controle por parte os tribunais ou do legislador.

Compondo um enorme acervo de dados, o chamado big data na rede mundial de computadores, distribuídos em imensa velocidade como uma verdadeira torrente, corre-se o risco de perda da privacidade.

Nesse contexto, a tecnologia blockechain está, de mesma maneira, inserida nesse sistema torrencial de informações, inseridas em uma tecnologia que, como qualquer outra, em relação a seu uso, "pode gerar consequências imprevisíveis e incontroláveis"18, sendo que pode muitas vezes, após grande cuidado, ser necessária sua desativação ou restruturação.

De acordo com Moore, desde o final da década de 1990, podem-se deduzir três características centrais, a saber: o uso da informação como recurso econômico; a difusão do uso da informação como setor próprio da economia; e o desenvolvimento da informação como um setor próprio da economia ${ }^{19}$.

Rodotà $^{20}$ destaca que a fragmentação da pessoa reduzida a dados pode ser tanto utilizada como mecanis-

${ }_{16}$ ROSAS, Eduarda Chacon. Alcance resultados, mas não se esqueça dos propósitos: a dignidade, a ética e os elevados fins. In: MALDONALDO, Viviane Nóbrega; FEIGELSON, Bruno. Advocacia 4.0. São Paulo: Revista dos Tribunais, 2019. p. 211.

17 SOUZA, Eduardo Nunes de. Perspectivas de aplicação do abuso de direito às relações existenciais. In: TEPEDINO, Gustavo; TEIXEIRA, Ana Carolina Brochado; ALMEIDA, Vitor. O Direito Civil entre o sujeito e a pessoa. Belo Horizonte: Fórum, 2016. p. 59.

18 MAGRANI, Eduardo; SILVA, Priscilla; VIOLA, Rafael. Novas perspectivas sobre ética e responsabilidade de inteligência artificial. In: FRAZ̃̃O, Ana; MULHOLLAND, Caitlin. Inteligência artificial e direito. São Paulo: Revista dos Tribunais, 2019. p. 117.

19 MOORE, Nick. The information Society. In: UNESCO. World information report 1997/1998. Paris: Unesco, 2007. Cap. 20, p. 271. ${ }^{20}$ RODOTÀ, Stefano. Transformações do corpo. Revista Trimestral 
mo de proteção como para atividades ilegais em relação à pessoa, essencialmente utilizando-se de seus dados biométricos, cuja base é a justamente a peculiaridade do usuário, como se tornasse o corpo uma própria senha.

Nesse novo ambiente virtual, dados pessoais ou dados sensíveis são facilmente teletransportados, essencialmente ao que hoje intitulam-se nuvens, formando-se o que se denomina "sombra de dados" ou data shadow - informações pessoais que pessoas diariamente deixam quando participam de atividades diárias via online, ao que se deve tomar todo o cuidado de não reduzir a pessoa a um número, uma matéria-prima, essencialmente quando esta precisa de privacidade e proteção de seus direitos de personalidade ${ }^{21}$.

Dessa forma, o uso dessa tecnologia não poderá passar despercebido pelo crivo das ciências sociais, do direito e suas finalidades de proteção ao ser humano, o qual não poderá ser reduzido em sua humanidade.

Isso porque, e relação a esse novo cenário de hiperconectividade na Era da Internet das Coisas, as inovações como a do blockechain, deverão ser pensadas de modo que os parâmetros que norteiem a sociedade cada vez mais moldada pela tecnologia possam atender aos fins sociais e humanos ${ }^{22}$.

Com essa preocupação, acerca das novas tecnologias, em 16 de fevereiro de 2017, o Parlamento Europeu editou resolução com recomendações da Corte Europeia acerca das regras aplicáveis sobre a robótica, realçando, dentre outras questões, acerca das "pessoas eletrônicas" ou "e-persons" e seus impactos sobre as pessoas naturais, sendo que, considerando um cenário de desconexão entre a ética e a tecnologia, a diretriz europeia afirma que a dignidade deverá ser o centro de uma nova ética digital23.

de Direito Civil, Rio de Janeiro: Padma, v. 5, n. 19, jul./set. 2004. p. 93. ${ }^{21}$ SCHULMAN, Gabriel. www.privacidade-em-tempos-deinternet.com: $\mathrm{O}$ espaço virtual e os impactos reais à privacidade. In: TEPEDINO, Gustavo; TEIXEIRA, Ana Carolina Brochado; ALMEIDA, Vitor. O direito civil entre o sujeito e a pessoa. Belo Horizonte: Fórum, 2016, p. 347.

${ }^{22}$ MAGRANI, Eduardo. A internet das coisas. Rio de Janeiro: FGV, 2018. p. 24. Disponível em: https://bibliotecadigital.fgv.br/dspace/ bitstream/handle/10438/23898/A\%20internet $\% 20$ das\%20coisas. pdf? sequence $=1 \&$ is Allowed $=\mathrm{y}$. Acesso em: 22 abr. 2021.

${ }^{23}$ HÄUSER, Markus. Do robots have rights? The European Parliament addresses artificial intelligence and robotics. Lexology: CMS Germany. Disponível em: https://www.lexology.com/library/detail.aspx?g=8233438f-4ad0-432a-a27e-0018f41468f3. Acesso em: 22 abr. 2021
Para a diretora adjunta da The Engine Room, organização sem fins lucrativos que apoia a sociedade civil no avanço de missões por meio do uso estratégico, responsável por dados e tecnologia, Zara Rahman, especialista em tecnologia e poder, considerando-se raça e identidade $^{24}$, pode-se afirmar o caráter duvidoso em relação à ética, a respeito da realização de experiências com populações vulneráveis, uma vez que a coleta maciça de informações e de identificação catalogada por meios análogos ao da biometria tem sido historicamente um grande problema para as pessoas em situação de migração, tal como ocorrera na época do holocausto, ou na terrível limpeza étnica de Rohingya em Mianmar ${ }^{25}$.

O direito internacional, desde suas bases iniciais, é reconhecido no direito ocidental tradicionalmente como um sistema dinâmico que visa disciplinar e regulamentar as atividades exteriores a atividade dos Estados, bem como das organizações internacionais e dos próprios indivíduos ${ }^{26}$, e tem como objetivo regular a relação entre os interesses dos Estados e da sociedade global.

Importante destaque de Mazzuoli ${ }^{27}$ é a necessária separação entre pertencer à sociedade internacional e ser sujeito de direito internacional. Dessa forma, mencionar atores internacionais é algo muito mais amplo do que sujeitos do direito internacional, preferindo-se aludir-se a atores internacionais, englobando Organizações Não Governamentais - ONGs, e outras entidades que não detêm personalidade jurídica, as quais participam de mesma forma ativamente da sociedade internacional.

Destaca-se o caráter descentralizado da ordem da sociedade mundial, organizada em caráter cooperativo pelo direito internacional em prol da paz e segurança internacional, respeitando-se a interdependência, devendo sempre gerir a questão de que é atingido por regulamentos, muitas vezes não jurídicos, alheios ao seu

${ }^{24}$ RAHMAN, Zara. About me now. Blog Zahahanet. Disponível em: https://zararah.net/about/. Acesso em: 22 abr. 2021.

25 JUSKALIAN, Russ. Inside the Jordan refugee camp that runs on blockchain. Massachussets: Mit Technology Review. May/Jun. 2018. Disponível em: https://www.technologyreview.com/s/610806/ inside-the-jordan-refugee-camp-that-runs-on-blockchain/. Acesso em: 22 abr. 2021.

26 CARREAU, Dominique. Droit Internacional. 8. ed. Paris: A. Pedone, 2004. p. 24-32.

27 MAZZUOLI, Valério de Oliveira. Curso de Direito Internacional Público. 5. ed. São Paulo: Revista dos Tribunais, 2011. p. 58. 
campo de atuação, que ao mesmo tempo deve interagir e discipliná-los, dentro do fenômeno da globalização ${ }^{28}$.

Essa tendência de cooperação internacional, intensificada após a Segunda Guerra mundial, tendo em vista as atrocidades cometidas por Estados autoritários, transformou os direitos humanos de opções nacionais para uma responsabilidade internacional em prol da paz e segurança não apenas das nações, mas de toda a humanidade ${ }^{29}$.

$\mathrm{Na}$ atualidade, segundo Mont'Alverne e Matos ${ }^{30}$, "a globalização, com sua velocidade para a constituição de relações jurídicas, promove uma relativização espacial em que cada vez mais são realizadas atividades extraterritoriais, provocando uma internacionalização de todo o direito".

Assim, os avanços tecnológicos e as suas promessas de melhoramentos na vida humana obrigatoriamente deverão vir pautadas de disciplinas e debates das formas de garantias que possam preservar sempre a dignidade da pessoa humana.

Para a realização de uma análise crítica necessária, justifica-se, dentro da próxima seção a pesquisa empírica, utilizando-se da pesquisa qualitativa, por meio da aplicação de métodos e técnicas com o objetivo de proporcionar uma análise mais aprofundada de processos ou relações sociais, no sentido de analisar uma maior quantidade de informações dentro dos fatos que permitam demonstrar seu objeto de estudo em sua complexidade, em suas múltiplas características e relações ${ }^{31}$.

Assim, utiliza-se do estudo de caso, conjugando-se métodos, com base na análise de um fenômeno ou grupo específico ${ }^{32}$. A experiência empírica apresentou

${ }^{28}$ MAZZUOLI, Valério de Oliveira. Curso de Direito Internacional Público. 5. ed. São Paulo: Revista dos Tribunais, 2011. p. 59.

29 TEIXEIRA, Carla Noura. Por uma nova ordem internacional: Uma proposta de constituição mundial. 2009, 306 f. Tese (doutorado). Programa de Pós Graduação em Direito. Pontifícia Universidade Católica de São Paulo, São Paulo, 2009. p. 126-127.

${ }^{30}$ MONT'ALVERNE, Tarin Cristino Frota; MATOS, Ana Caroline Barbosa Pereira. Crônicas de Direito Internacional Público - A política australiana de refúgio e a decisão da suprema corte de Papua Nova Guiné: A ilegalidade do centro de detenção offshore. Revista de Direito Internacional, Brasília, v. 14, n. 3, 2017. p. 5

31 IGREJA, Rebecca Lemos. O Direito como objeto de estudo empírico: o uso de métodos qualitativos no âmbito da pesquisa empírica em Direito. In: MACHADO, Maíra Rocha (org.). Pesquisar empiricamente o Direito. São Paulo: Rede de Estudos Empíricos em Direito, 2017. p. 14.

32 IGREJA, Rebecca Lemos. O Direito como objeto de estudo empírico: o uso de métodos qualitativos no âmbito da pesquisa ao mundo um dos pioneiros usos experimentais da tecnologia blockchain para ajuda humanitária, aplicada aos refugiados sírios situados na Jordânia, a partir dos primeiros meses do ano de 2017.

\section{A experiência do uso do blockchain pela ONU na Jordânia no caso dos refugiados sírios}

O caso paradigmático da utilização do uso do blockchain sobre os refugiados sírios na região da Jordânia conduz aos elementos iniciais do debate relacionado à aplicação dessa tecnologia a essas populações hipervulneráveis, ou seja, que possuem vulnerabilidades sobrepostas. O caso em tela, dessa forma, viabiliza a construção dos pontos de partida para que se possa oferecer uma representação do fenômeno, em um contexto específico, com base nos dados e informações já fornecidos $^{33}$, em uma meta-análise.

A guerra civil Síria, também conhecida como Revolta síria ou Revolução síria, como ficou conhecida, foi iniciada em meados do ano de 2011, com base na ocorrência de uma série de protestos populares que progrediu para uma violenta revolta armada com o objetivo de destituir o então presidente Bashar al-Assad, para instauração de uma nova liderança democrática ${ }^{34}$.

Nesse contexto, o governo passou a considerar publicamente os líderes dessa revolta como terroristas que visam desestabilizar o país. Em 2013, a situação foi agravada com a reinvindicação de territórios da Síria por parte do Estado Islâmico, causando ainda mais violações de direitos dos civis, que se viram diante dos avanços desses grupos, sendo vilipendiados em seus direitos mais básicos.

Dada essa conjuntura, muitos civis procuraram refúgio em países de parte da Europa ou países mais próximos, como Líbano e Jordânia, ocasionando uma grande onda migratória, fugindo das atrocidades ocorridas em

empírica em Direito. In: MACHADO, Maíra Rocha (org.). Pesquisar empiricamente o Direito. São Paulo: Rede de Estudos Empíricos em Direito, 2017. p. 15.

33 MACHADO, Maira Rocha. Estudo de caso na pesquisa em direito. In: MACHADO, Maira Rocha (org.). Pesquisar empiricamente o direito. São Paulo: Rede Empírica de Estudos do Direito, 2017. p. 357 34 ENCYPLOPAEDIA BRITANNICA. Syrian civil war. Britannica, 2020. Disponível em: https://www.britannica.com/event/SyrianCivil-War. Acesso em: 26 abr. 2021. 
seu país de origem, crimes de guerra e contra a humanidade perpetrados nas revoltas armadas, bem como da fome e da miséria que se agravavam perante a ocorrência de tais fatos.

A violência local ainda persiste, o enfrentamento entre tropas governamentais e os chamados jihadistas, termo comumente utilizado no ocidente para designar grupos muçulmanos que entendem ser a luta armada necessária para a implementação da sharia, a interpretação da lei muçulmana no sentido de organizar politicamente a sociedade de acordo com suas normas ainda ocasiona muitas ondas de violência e, consequentemente, intensifica a migração ${ }^{35}$.

Dessa forma, muitos deixaram seus lares sem documentos, muitas vezes tão somente com as roupas as quais trajavam, viajando de forma arriscada em amontoados de pessoas transportadas em cargas terrestres ou navios em busca de refúgio em locais onde possam recomeçar suas vidas de um modo digno, ou mesmo simplesmente sobreviver, muitas vezes tendo pessoas mortas em suas famílias, porém longe de conflitos belicosos.

Nesse contexto, em meados de 2017, a Organização das Nações Unidas - ONU, lançou um programa de ajuda humanitária aplicado de modo experimental aos grupos de refugiados sírios que se situavam no território da Jordânia, utilizando de uma tecnologia disruptiva, com a finalidade não apenas de garantir a alimentação dessas pessoas, como também a segurança e a economia nas transações necessárias para obter tais alimentos, tendo sido elas colocadas à disposição para o uso dessa tecnologia.

Em junho de 2017, realizou-se evento de cúpula do ID2020, um consórcio público-privado firmado, dentre outros objetivos, o desenvolvimento de um protótipo de uma identidade legal para todos no planeta ${ }^{36}$. A parceria, na ocasião, firmada com a Organização das Nações Unidades - ONU, teve como meta a promoção do objetivo 16 da agenda de Desenvolvimento Sustentável 2030, direcionado ao fornecimento de uma identidade legal para todos, incluindo o registro de nascimento ${ }^{37}$.

\footnotetext{
35 BBC. O que é o jihadismo? News Brasil: BBC, 2014. Disponível em: https://www.bbc.com/portuguese/noticias/2014/12/141211_ jihadismo_entenda_cc. Acesso em: 26 abr. 2021.

${ }^{36}$ ID2020. We need to get digital ID right. Disponível em: https:// id2020.org/. Acesso em: 22 abr. 2021.

37 UNITED NATIONS. Transforming our world: the 2030 Agenda for Sustainable Development. UN Platform, 2015. Disponível em: https://sustainabledevelopment.un.org/post2015/transforming-
}

O evento ocorreu na sede da ONU, ocasião em que a Accenture e a Microsoft uniram-se com o escopo de desenvolver um protótipo de rede de identificação digital utilizando-se de tecnologia conhecida usualmente como blockchain, como parte de um projeto para fornecer, em escala mundial, identificação legal a 1,1 bilhão de pessoas as quais não possuam seus documentos oficiais, com o objetivo essencial de auxiliar refugiados a buscarem os serviços mais básicos como educação, saúde e alimentação ${ }^{38}$.

Assim, o projeto teve como ponto de partida a premissa de que a identidade, nesse sentido, é um direito humano básico. O modelo estudado foi desenvolvido sobre uma plataforma de propriedade da Accenture, encarregada de alimentar o sistema de gerenciamento de identidade através de dados biométricos a serem colhidos dos refugiados ${ }^{39}$.

A partir desse protótipo, Houman Haddad, chefe de tecnologias emergentes do Plano Mundial de Alimentos - PMA, idealizou a utilização dessa ferramenta tecnológica como um sistema de transferência de renda, sendo então lançado, em 2017, o maior projeto piloto do uso do blockechain sobre o setor humanitário. Ao final do ano de 2019, o projeto chegou a atender 110.000 pessoas nos campos de refugiados sírios de Azraq e Zaatari, na Jordânia ${ }^{40}$, em parceria com a Parity Technologies e a Baltic Data Science, com base no Ethereum - uma forma de criptomoeda digital, para sua atual infraestrutura financeira baseada nessa tecnologia ${ }^{41}$.

Destaca-se que, inicialmente, a tecnologia fora antes testada no Paquistão. A forma com que foi utilizada, fez

ourworld. Acesso em: 22 abr. abr. 2021.

38 IRRERA, Anna. Accenture, Microsoft team up on blockchainbased digital ID network. Technology News: Reuters, 2017. Disponível em: https://www.reuters.com/article/us-microsoft-accenture-digitalid/accenture-microsoft-team-up-on-blockchain-based-digital-idnetwork-idUSKBN19A22B. Acesso em: 22 abr. 2021.

${ }^{39}$ IRRERA, Anna. Accenture, Microsoft team up on blockchainbased digital ID network. Technology News: Reuters, 2017. Disponível em: https://www.reuters.com/article/us-microsoft-accenture-digitalid/accenture-microsoft-team-up-on-blockchain-based-digital-idnetwork-idUSKBN19A22B. Acesso em: 22 abr. 2021.

40 THE NATIONAL FUTURE. How blockechain technology has changed the game for Syrian refugees in Jordan. Abu Dhabi, 2019. Disponível em: https://www.thenational.ae/arts-culture/how-blockchain-technology-has-changed-the-game-for-syrian-refugees-in-jordan-1.932432. Acesso em: 22 abr. 2021.

${ }^{41}$ JI-HYOUNG, Son. Tech disruption plays out in WFP humanitarian initiative. Seul: The Investor, 2019. Disponível em: http:// www.theinvestor.co.kr/view.php?ud $=20190905000902$. Acesso em: 22 abr. 2021. 
com que as transações realizadas com essa tecnologia fossem lentas e com taxas muito altas. Haddad decidiu que um dos problemas era que o sistema foi construído no blockechain em uma versão pública, em que qualquer pessoa poderá utilizar a rede e validar transações. Dessa forma, ainda que haja dificuldade em adulteração ou falsificação das transações, as taxas se acumulavam e se tornavam mais altas ${ }^{42}$.

Por outro lado, também introduz um ponto notável de ineficiência: trabalhar com bancos locais ou regionais. Para o PMA, que transferiu mais de US $\$ 1,3$ bilhão em tais benefícios no ano de 2017 (cerca de 30\% de sua ajuda total), as transações e outras taxas são dinheiro que poderia ter sido gasto em milhões de refeições ${ }^{43}$.

Por meio de uso de máquinas para escanear a íris de refugiados cadastrados, confirma-se sua identidade em um banco de dados tradicional das Nações Unidas, consulta-se uma conta da família mantida em uma variante do chamado blockchain Ethereum pelo Programa Mundial de Alimentos - PMA, e assim o refugiado poderá pagar suas contas para se alimentar sem a necessidade da utilização de dinheiro, ao mesmo tempo em que se obtém uma visão em tempo real das transações ${ }^{44}$.

Dessa forma, essa ajuda aos refugiados da Síria seria distribuída como algo análogo a um voucher de criptomoedas que podem ser utilizados em mercados aderentes, permitindo assim um maior controle de gastos e a detecção de possíveis fraudes.

O programa, conhecido como Building Blocks, passou a auxiliar a distribuição de ajudas para mais de 100.000 refugiados sírios na Jordânia. Até o final do ano de 2018, cobriu todos os 500 mil refugiados no país. Acaso bem sucedido, o projeto almeja acelerar a aderência ao uso das tecnologias disruptivas do blockchain nas agências da

\footnotetext{
${ }^{42}$ JUSKALIAN, Russ. Inside the Jordan refugee camp that runs on blockchain. Massachussets: Mit Technology Review, May/Jun. 2018. Disponível em: https://www.technologyreview.com/s/610806/ inside-the-jordan-refugee-camp-that-runs-on-blockchain/. Acesso em: 22 abr. 2021.

${ }^{43}$ JUSKALIAN, Russ. Inside the Jordan refugee camp that runs on blockchain. Massachussets: Mit Technology Review, May/Jun. 2018. Disponível em: https://www.technologyreview.com/s/610806/ inside-the-jordan-refugee-camp-that-runs-on-blockchain/. Acesso em: 22 abr. 2021.

${ }^{44}$ JUSKALIAN, Russ. Inside the Jordan refugee camp that runs on blockchain. Massachussets: Mit Technology Review, May/Jun. 2018. Disponível em: https://www.technologyreview.com/s/610806/ inside-the-jordan-refugee-camp-that-runs-on-blockchain/. Acesso em: 22 abr. 2021.
}

ONU e mesmo em outros casos de refugiados ao longo do mundo 45 .

O programa iniciou a concessão de acesso direto a quantias em dinheiro aos titulares de contas, prevendo-se, no futuro, um conceito de "carteira múltipla", segundo o qual as pessoas poderiam usar o sistema para pagar por outros bens, como educação, histórico de viagens e saúde, almejando expandir sua incidência em outros grupos de refugiados, como os que migraram para Bangladesh e Palestina ${ }^{46}$.

Destarte, imagina-se que o refugiado possa portar consigo, posteriormente, uma forma de "carteira digital" de seus dados e metadados, podendo ser armazenada até mesmo em um telefone celular preenchida com o histórico de transações do acampamento em que se encontre, bem como a identificação do governo e o acesso a contas financeiras, ligados por meio de um sistema de identidade baseado em tecnologia blockchain.

Com base nessa perspectiva, o formato desses dados seria criptografado dentro dos smartphones dos refugiados, podendo recuperar os dados de identidades perdidas quando necessitaram abandonar suas casas em sua terra natal, o que facilitaria comprovação futura sobre sua educação, vacinas ou outros dados em uma eventual mudança de país, facilitando sua permanência de modo legalizado ${ }^{47}$.

Nesse contexto, o refugiado poderia entrar com mais facilidade na economia mundial, possuindo um local para um possível empregador depositar pagamentos, ou para um banco visualizar seu histórico de crédito e até mesmo para um agente imigração verificar sua identidade, devidamente atestado pela ONU e pelo governo jordaniano $^{48}$.

${ }^{45}$ JUSKALIAN, Russ. Inside the Jordan refugee camp that runs on blockchain. Massachussets: Mit Technology Review, May/Jun. 2018. Disponível em: https://www.technologyreview.com/s/610806/ inside-the-jordan-refugee-camp-that-runs-on-blockchain/. Acesso em: 22 abr. 2021.

46 THE NATIONAL FUTURE. How blockechain technology has changed the game for Syrian refugees in Jordan. Abu Dhabi, 2019. Disponível em: https://www.thenational.ae/arts-culture/how-blockchain-technology-has-changed-the-game-for-syrian-refugees-in-jordan-1.932432. Acesso em: 22 abr. 2021.

${ }^{47}$ JUSKALIAN, Russ. Inside the Jordan refugee camp that runs on blockchain. Massacbussets: Mit Technology Review, May/Jun. 2018. Disponível em: https://www.technologyreview.com/s/610806/ inside-the-jordan-refugee-camp-that-runs-on-blockchain/. Acesso em: 22 abr. 2021.

48 JUSKALIAN, Russ. Inside the Jordan refugee camp that runs on blockchain. Massachussets: Mit Technology Review, May/Jun. 2018. 
Para os entusiastas do uso dessa tecnologia, haveria benefícios tanto aos refugiados como para as nações anfitriãs, uma vez que essa experiência poderá ser desenvolvida até chegar-se ao denominado "passaporte global", evitando-se inclusive a possibilidade de migração de fugitivos criminosos de guerra ou uma burocratização excessiva daqueles que necessitariam dos serviços mais básicos para uma vida digna. Isso auxiliaria no problema da governança na política de imigração ${ }^{49}$.

Não obstante, com base nesses dados qualitativos do estudo do caso, deve-se buscar a análise das variáveis possíveis, considerando-se o objetivo central de compreender as relações envolvidas a respeito da observação de sua evolução, almejando-se a generalização do substrato $^{50}$, em busca posterior da teorização em prol da proteção da pessoa humana em sua dignidade de modo integral.

Mas as expectativas do Building Blocks são grandes por parte dos idealizadores do projeto, sendo uma das várias maneiras pelas quais o blockchain pode ser usado no setor. O Conselho Norueguês para os Refugiados analisa que a tecnologia oferece uma abordagem revolucionária ao propor confiança na plataforma e não entre as pessoas, ao mesmo tempo em que fornece freios e contrapesos no sistema. Não obstante, nenhum dos projetos humanitários da atualidade são sistemas perfeitos devido à persistente necessidade de ainda se utilizar de procedimentos em papel para fins de verificação e auditoria. Um grande desafio apontado, nesse sentido, seria a funcionalidade offline em locais sem conexão com a rede mundial de computadores, como é a realidade de muitos campos de refugiados. ${ }^{51}$

Disponível em: https://www.technologyreview.com/s/610806/ inside-the-jordan-refugee-camp-that-runs-on-blockchain/. Acesso em: 22 abr. 2021.

49 O'NEAL, Stephen. DLT in Migration Policy: How Blockchain Can Help Both Refugees and Host Nations. Cointelegraph, 2018. Disponível em: https://cointelegraph.com/news/dlt-in-migrationpolicy-how-blockchain-can-help-both-refugees-and-host-nations? $\mathrm{ga}=2.157462527 .436306420 .1587005638-1708324271.1584115364$. Acesso em: 15 abr. 2020.

${ }^{50}$ GÜNTHER, Hartmut. Pesquisa qualitativa versus pesquisa quantitativa: Esta é a questão? Psicologia: Teoria e pesquisa. Brasília: Unb. v. 22, n. 2. maio/ago. 2006. p. 201-205.

51 THE NATIONAL FUTURE. How blockechain technology has changed the game for Syrian refugees in Jordan. Abu Dhabi, 2019. Disponível em: https://www.thenational.ae/arts-culture/how-blockchain-technology-has-changed-the-game-for-syrian-refugees-in-jordan-1.932432. Acesso em: 22 abr. 2021.
Outro grande desafio levantado foi a detecção de material ilícito inserido em bitcoins, o maior usuário da tecnologia do blockechain, vinculando-o à chamada dark $w_{e} b^{52}$, uma forma de acesso à rede mundial de computadores destinada ao anonimato, possui um vasto conteúdo considerado ilegal por diversos países, vinculada ao mercado de drogas, armas, hacking entre outras atividades contrárias ao Direito ${ }^{53}$.

Da mesma forma que demonstrou abertura para a prática de atos ilícitos dentro do uso dessa ferramenta, poderia ocorrer com a utilização de dados de refugiados, que já se encontram em uma situação de hipervulnerabilidade.

O fator preocupante é que, ainda que muito dificilmente invadida, a tecnologia do blockechain não é de todo segura, havendo risco de invasão, roubo de identidade, fraude, cyberclones, além da necessidade de aceitação de quem possua a tecnologia, podendo ocasionar uso indevido dos dados sensíveis do refugiado para fins ilícitos.

De toda sorte, apresentou-se ao mundo um novo modelo de negócios em que o pagamento é realizado em troca da privacidade dos dados mais sensíveis de um ser humano, sendo esses dados a condição de uso ou mesmo a própria moeda de troca, sendo inerente a sua própria natureza.

Apropriando-se da crítica à tecnologia de Tapscott ${ }^{54}$, enumeram-se muitos obstáculos a serem superados, como o fato de o valor equivalente a dinheiro não poder ser cedido mais de uma vez, como ocorreria com outros bens de informação ou propriedade intelectual, tal qual uma fotografia. Além disso, muitas vezes os poderes centrais de governo se sobrepõem à questão da coleta de informações, que estão além de meros dados econômicos, podendo não configurar um controle financeiro, mas sim de dados pessoais.

\footnotetext{
52 THE NATIONAL FUTURE. How blockechain technology has changed the game for Syrian refugees in Jordan. Abu Dhabi, 2019. Disponível em: https://www.thenational.ae/arts-culture/how-blockchain-technology-has-changed-the-game-for-syrian-refugees-in-jordan-1.932432. Acesso em: 22 abr. 2021.

53 BARBOSA, Daniel Cunha. Os mistérios da Dark Web: descubra o que essa rede tem a oferecer e por que pode ser tão perigosa. São Paulo: Eset Brasil, 2019. Disponível em: https://www.welivesecurity.com/br/2019/05/17/os-misterios-da-dark-web-descubra-o-queessa-rede-tem-a-oferecer-e-por-que-pode-ser-tao-perigosa/. Acesso em 22 abr. 2021.

${ }^{54}$ TAPSCOTT, Don; TAPSCOTT, Alex. Blockchain Revolution. São Paulo: SENAI-SP, 2016. p. 3-39.
} 
Dessa forma, a informação emerge não apenas como uma classe de produto, sujeita a novas transações comerciais, como também sua apropriação ilícita ${ }^{55}$ ou contrária a ética e aos direitos humanos, devendo ser disciplinada pelo direito, considerando-se não apenas os aspectos da grande disruptura que provocou nos modos de realizar negócios ou gerir informações pessoais, ou pela questão do grande gasto de energia e poder computacional que demanda, o que demandaria um alto custo de capital inicial, mas sim o debate sobre a natureza e finalidade desse objeto, para que se possa ser disciplinado como bem jurídico tutelado, de modo a cumprir os interesses que envolvem e permeiam os direitos humanos, essencialmente no que tange à ética da utilização das informações sobre direitos de personalidade, bem como à segurança jurídica.

Outro problema a ser ponderado é o fato da confirmação das informações fornecidas pelos refugiados, quando da situação de não haverem como comprovar quem são ou seus dados mais básicos, enfrentando-se assim o risco de registro de falsidade ideológica.

Os pontos acima analisados devem ser considerados e discutidos como fatos jurídicos, capazes de gerar reconhecimento e disciplina pelo direito internacional, de maneira a garantir a efetividade, finalidade e a promoção dos direitos humanos, essencialmente no caso de refugiados, que se encontram em posição de vulnerabilidade e poderão enfrentar sérios problemas em outros países, como a xenofobia ou alguma forma de controle invasivo e excludente, a partir da posse de seus dados.

Isso porque devem-se considerar os riscos originados do uso da tecnologia essencialmente face à ausência de guidelines, ou linhas gerais a serem seguidas para utilização do blockechain em relação à organização ou tentativa de facilitação dos direitos dos refugiados, salientando que quando da aplicação de recursos tecnológicos, há de se ter ciência de quem será o provedor, quem mantem, como é o sigilo, como é o respeito aos direitos fundamentais expostas a isso, como cumprir os princípios básicos dos direitos dos refugiados. São pontuações que devem ser obrigatoriamente satisfeitas para que se possa pensar e uma principiologia fortalecida e protegida.

De fato, apesar dos riscos, há possibilidades a serem cogitadas acerca dos aspectos positivos do uso do

55 DELL. Underground hacker markets. Secure Words. Round Rock: Dell, 2014. p. 5 blokchain para além do PMA, mas como reflexões sobre a oferta de efetiva proteção a refugiados de outras ocasiões, como o importante tema da proteção dos refugiados indígenas, de modo a ser uma forma de salvaguardar suas especificidades culturais e as derivadas de suas terras tradicionais ${ }^{56}$.

Assim, poder-se-ia aplicar essa tecnologia como forma a salvaguardar a identidade cultural no processo de perda do elo com sua cultura logo que são forçados a sair de seu país de origem, em uma situação de perda, de choque, de ruptura. O blockchain poderia assim ser uma forma de guardar a cultura e ancestralidade dessa pessoa para protege-la e defende-la dentro de suas origens.

Dessa forma, poderia-se salvaguardar a tutela da pessoa hmana, evitando-se danos à sua existência e aos seus projetos de vida, já que, quando forçada a uma adaptação cultural por não ter outra opção, muitas vezes lhe é usurpada a viabilidade de condições de realizar sua própria cultura e acabar por evitar erosões, já que até mesmo a alimentação é uma questão cultural ${ }^{57}$.

A tecnologia pode trazer grandes vantagens assim como grandes riscos - justificando-se assim a necessidade da criação de padrões de conduta - guidelines dentro do direito internacional, mais especificadamente direcionado a essas populações que se encontram em situação de sobreposição de vulnerabilidades, ou seja, em hipervulnerabilidade.

\section{0 direito internacional dos refugiados como baliza interpretativa formadora de guidelines para o uso do blockchain}

A proteção dos direitos humanos, possui fortes bases filosóficas, essencialmente de matriz kantiana. Face ao Estado, desta forma, compõe-se a temática de sua justificativa política, buscando-se proteger o ser huma-

\footnotetext{
56 FIGUEIRA, Rickson Rios. Indigenous refugee and cultural erosion: possibilities and limits of international refugee and indigenous peoples law in the protection of indigenous cultural expression related to traditional land and traditional native languages. Revista de Direito Internacional, Brasília, v. 17, n. 3, 2020. p. 441.

57 FIGUEIRA, Rickson Rios. Indigenous refugee and cultural erosion: possibilities and limits of international refugee and indigenous peoples law in the protection of indigenous cultural expression related to traditional land and traditional native languages. Revista de Direito Internacional, Brasília, v. 17, n. 3, 2020. p. 448.
} 
no da violação de seus direitos mais básicos, evitando, assim, a repetição das atrocidades ocorridas ao longo da história mundial. Essa proteção é atemporal, devendo ser sempre adequada e reinterpretada à luz dos novos riscos.

Com efeito, não apenas as situações de guerra como o contínuo desenvolvimento da sociedade que paulatinamente aumenta seus riscos por atividade predatórias de pessoas de direito público e privado, na exploração das formas de energia, mídias, meios de informação, a industrialização, a padronização de comportamentos e de estilos de vida e atribuição desses próprios métodos de exploração predatória a todo e qualquer empreendimento fizeram com que a pessoa fosse usurpada de sua natureza humana e de sua existência, como se torne totalmente dependente das novas necessidades a ele impostas $^{58}$.

A criação da Organização das Nações Unidas ONU em 1945, organização intergovernamental de caráter universal e representativa da comunidade internacional, foi direcionada para atuar na manutenção da segurança e da paz internacionais, desenvolver relações amistosas entre os Estados, bem como fomentar a cooperação entre povos, especialmente na sistematização e efetivação dos direitos humanos, além de funcionar como centro harmonizador das ações internacionais, promovendo a internacionalização dos direitos humanos, protegidos mesmo que em situação de ausência de guerras internacionais.

O refúgio, como um dos braços de tutela do direito internacional dos direitos humanos ${ }^{59}$ não trata de um ato discricionário do Estado concessor, pois o reconhecimento do status de refugiado está vinculado a diplomas e hipóteses legais bem definidos, regulados pelas normas internacionais, que reconhecem esse direito como inerente ao ser humano.

O refugiado não se confunde com o migrante nem com o estrangeiro residente, possuindo assim fundamento de proteção próprio e normas próprias para sua tutela, corporificado pelo complexo sistema de proteção internacional, não se limitando à Convenção de Genebra, de 1951.

58 BECK, Ulrich. Sociedade de Risco: Rumo a uma outra modernidade. Trad. Sebastião Nascimento. São Paulo: Editora 34, 2011. p. 111

59 JUBILUT, Liliana Lyra O Direito internacional dos refugiados e sua aplicação no orçamento jurídico brasileiro. São Paulo: Método, 2007. p. 42-43.
Esse instituto, enquanto estrutura normativa complexa composta por uma pluralidade de normas e modelos jurídicos subordinados a exigências comuns de ordens e princípios superiores, surge no início do século XX, sob o amparo da Liga das Nações, ante a um grande contingente de pessoas perseguidas durante a e após a Segunda Guerra Mundial, tornando inviável a qualificação individual pelo instituto do asilo, demandando-se uma qualificação coletiva que assegurasse proteção internacional dentro de padrões mínimos a serem resguardados, tendo os Estados a faculdade de aumentar o rol de proteção e de hipóteses para o reconhecimento do status de refugiado ${ }^{60}$. Nesse sentido,

a proteção internacional dos refugiados se opera
mediante uma estrutura de direitos individuais e
responsabilidade estatal que deriva da mesma base
filosófica que a proteção internacional dos direitos
humanos. O Direito Internacional dos Direitos
Humanos é a fonte dos princípios de proteção dos
refugiados e ao mesmo tempo complementa tal
proteção ${ }^{61}$.

Conforme Jubilut ${ }^{62}$, Direito Internacional dos Direitos Humanos e o Direito Internacional dos Refugiados apresentam o mesmo objeto - a proteção da pessoa humana na ordem internacional; mesmo método - as regras internacionais assecuratórias; mesmos sujeitos - o ser humano como beneficiário e o Estado como destinatário e obrigado principal do cumprimento das normas; mesmos princípios e finalidades - a dignidade da pessoa humana, a garantia do respeito a esta; e a garantia da não-discriminação, diferindo-se apenas no conteúdo de suas regras, em função de seu âmbito de aplicação.

Sendo uma vertente do Direito Internacional dos Direitos Humanos, a proteção dos refugiados, base do que se convencionou denominar de "Direito Internacional dos Refugiados" também padece de fundamentos filosóficos consensuais, residindo a força de sua justificativa em bases menos palpáveis, como a filosofia, a moral e a ética, o que, de certo modo, enfraquece a sua efetivação. Assim, por essa razão, foi reconhecida a ne${ }^{60}$ JUBILUT, Liliana Lyra O Direito internacional dos refugiados e sua
aplicação no orçamento jurídico brasileiro. São Paulo: Método, 2007. p. 43-
45.
${ }^{61}$ PIOVESAN, F. O direito de asilo e a proteção internacional dos
refugiados. In: ALMEIDA, G. A. e ARAÚJO, N. O Direito Internac-
ional dos Refugiados: uma perspectiva brasileira. Rio de Janeiro: Reno-
var, 2001. p. 37 .
62 JUBILUT, Liliana Lyra O Direito internacional dos refugiados e sua
aplicação no orçamento jurídico brasileiro. São Paulo: Método, 2007. p. 60. 
cessidade de criação e positivação internacional de um instituto assecuratório específico da proteção a pessoas perseguidas em função de suas liberdades fundamentais, tendo como grande desafio a sua efetivação, a qual depende dos Estados em sua soberania ${ }^{63}$.

Essa principiologia extraída do Direito Internacional dos Refugiados pauta-se no Princípio da Solidariedade direcionado a um acolhimento e soluções duradouras para aqueles que foram forçados a se deslocar, com condições civis e de cidadania que permita sua locomoção e tentativa de continuidade de seu projeto de vida, acaso possível, ou de um novo projeto, garantindo-se seus interesses existenciais para que possam suprir suas necessidades mais básicas e escolhas em sua história dentro de uma vida digna.

A solidariedade, antes de ser um princípio, é um dos sentimentos encontrados há mais tempo na raça humana, constituindo um dos valores maiores para a construção dos direitos humanos, uma vez que sem ela não há reconhecimento do estado de pessoa e, consequentemente, dos próprios direitos humanos. Sob esse prisma, trata-se do mais profundo fundamento filosófico da concessão de refúgio, uma vez que a proteção do ser humano é de responsabilidade de todos ${ }^{64}$.

Tal solidariedade é justificada dado que o refugiado se encontra em situação de sobreposição de sua vulnerabilidade. A situação de não ter escolha e ter de deixar o próprio país, considerando-se que um grande temor já faz com que a pessoa esteja vulnerável, muitas vezes sem a documentação completa, limitando a possibilidade de abrir e manter contas bancárias, matricular-se em cursos ou matricular seus filhos para exercício do direito à educação.

Muitas vezes, enquanto aguardam a análise dos atributos políticos da condição de refugiados, tendo seu direito de circular restringido, são direcionados a abrigos mantidos por entidades governamentais; e caso sintam-se sem condições de ali permanecer, procuram abrigo em locais vagos ou abandonados ou mesmo vagam em ruas de cidade, expostos a situação de alto risco, e às

\footnotetext{
${ }^{63}$ JUBILUT, Liliana Lyra O Direito internacional dos refugiados e sua aplicação no orçamento jurídico brasileiro. São Paulo: Método, 2007. p. 6264.

${ }^{64}$ JUBILUT, Liliana Lyra O Direito internacional dos refugiados e sua aplicação no orçamento jurídico brasileiro. São Paulo: Método, 2007. p. 67-69.
}

vezes acabam ignorados pela sociedade, em um quadro de vulnerabilidades invisíveis ${ }^{65}$.

Isso se deve ao fato de que, muitas vezes, o aumento do tempo de espera pelo reconhecimento ao refúgio nos campos de refugiados materializa um processo de segregação e mesmo exclusão social.

De fato, o refúgio não concede um status permanente, mas sim móvel em uma solução duradoura, podendo ser o retorno ao seu país quando da cessação do temor que causou seu pedido de conceção de refúgio, ou mesmo direcionamento para países de acolhimento.

Nesse sentido, o blockchain poderia facilitar e mesmo acelerar a conferência dos requisitos legais para concessão do refúgio e regularização da permanência, viabilizando o exercício dos direitos civis mais básicos como saúde, educação, trabalho e mesmo evitar captação de refugiados para fins de tráfico humano, dado que o "passaporte" para os dados pessoais seriam seus dados biométricos.

Pontua-se que não há um padrão que crie uma rotina ou um procedimento determinado acerca de como os países que acolhem deverão proceder, não havendo um sistema próprio que uniformize, por exemplo, a concessão da documentação necessária para o exercício dos direitos inerentes ao refugiado.

Em geral, os países de acolhida buscados pelos que buscam refúgio são os que já têm referência em direitos humanos, ou seja, que ao menos tenham assinado e ratificado as convenções das nações unidas sobre os Direitos dos Refugiados.

Contudo, ainda assim podem ocorrer desvios, como no caso das medidas australianas denominadas "Solução do Pacífico" em 2012, na ocasião em que o país transferiu seus centros de detenção para fora de seu território, não submetidos às leis australianas, e, por meio de um memorando de entendimento com a Papua Nova-Guiné, enviou os solicitantes de refúgio para centros de detenção na Ilha Manus, em troca de vantagens econômicas ${ }^{66}$. ${ }_{65}$ FIGUEIRA, Rickson Rios. Indigenous refugee and cultural ero-
sion: possibilities and limits of international refugee and indigenous
peoples law in the protection of indigenous cultural expression re-
lated to traditional land and traditional native languages. Revista de
Direito Internacional, Brasília, v. 17, n. 3, 2020. p. 451-454.
${ }_{66}$ MONT'ALVERNE, Tarin Cristino Frota; MATOS, Ana Caro-
line Barbosa Pereira. Crônicas de Direito Internacional Público - A
política australiana de refúgio e a decisão da suprema corte de Papua 
Em publicação do mesmo ano, do Alto Comissariado das Nações Unidas para Refugiados - ACNUR, foram expedidas diretrizes para a detenção de solicitantes de refúgio, em respeito à liberdade de ir e vir e segurança do refugiado, que não pode sofrer com uma detenção arbitrária, sem o devido processo legal e ainda que assim o seja, as condições devem ser humanas e dignas ${ }^{67}$.

Outro exemplo ocorrera no ano de 2016, a respeito de um acordo travado entre União Europeia e Turquia, em que todos os migrantes que fugiam da guerra síria, não ainda oficialmente refugiados, acaso fossem considerados irregulares, quando do desembarque em solo grego, seriam devolvidos ao território turco ${ }^{68}$.

Os Estados-Nações, quando assinam as convenções internacionais como no caso das normas de proteção aos refugiados, convencionam adequarem seus contornos jurídicos ao direito internacional, limitando sua soberania $^{69}$ dentro de um modelo cooperativo, em prol do recrudescimento de políticas humanistas.

Isso porque o Direito Internacional pauta-se na diversidade e no pluralismo, com base na tolerância e na alteridade, fundamentos do Princípio do non refoulement - "não devolução" aos seus países de origem sem que seja justificado por um grave e justo motivo, ou mesmo a cessação do risco para o solicitante. Esse princípio é, de acordo com Piovesan, a "pedra angular do direito dos refugiados" 70 .

Com a possibilidade de inserção de dados indevidos, acaso não haja certeza acerca de quem será o hospedeiro desses dados, e, essencialmente, quem terá a responsabilidade pelo sigilo e segurança destes, correm-se sérios riscos essencialmente quando se tenha um Estado tendencioso a não receber refugiados. Exemplificati-

Nova Guiné: A ilegalidade do centro de detenção offshore. Revista de Direito Internacional, Brasília, v. 14, n. 3, 2017. p. 4.

${ }^{67}$ ACNUR. Diretrizes sobre os critérios aplicáveis e os padrões relativos à detenção de solicitantes de refúgio, e soluções alternativas à detenção. Genebra: ACNUR, 2012.Disponivel em: https://www.refworld.org/cgi-bin/ texis $/$ vtx $/$ rwmain/opendocpdf.pdf? reldoc $=\mathrm{y} \&$ docid $=53 \mathrm{~d} 602884$ Acesso em 29 abr. 2021.

68 PIOVESAN. Flávia Cristina; OLSEN, Ana Carolina Lopes. Tolerância e refúgio: Um ensaio a partir do acordo EU-Turquia. Revista de Direito Internacional, Brasília, v. 14, n. 2, 2017. p. 221.

69 TEIXEIRA, Carla Noura. Por uma nova ordem internacional: Uma proposta de constituição mundial. 2009, 306 f. Tese (doutorado). Programa de Pós-graduação em Direito. Pontifícia Universidade Católica de São Paulo, São Paulo, 2009. p. 104.

70 PIOVESAN. Flávia Cristina. OLSEN, Ana Carolina Lopes. Tolerância e refúgio: Um ensaio a partir do acordo EU-Turquia. Revista de Direito Internacional, Brasília, v. 14, n. 2, 2017. p. 216. vamente, acaso um algorítimo, programa que utiliza de inteligência artificial para realizar tarefas programadas com ou sem supervisão humana, verificasse nos dados de um refugiado, este já fora vizinho de uma pessoa procurada por atos de terrorismo, poderia aplicar uma lógica enviesada entendendo que aquele que requer refúgio também o seria, negando-lhe seu direito, ao mesmo tempo reforçando o discurso de proteger o território do terrorismo, como não raro se observou como justificativa para negar refúgio.

Da mesma forma, outra elocubração seria acerca do controle de refugiados em períodos de calamidade mundial, tal qual ocorreu a partir da pandemia do COVID19, em que não se poderia jamais pensar no uso da tecnologia para prejudicar refugiados, em um período em que deveria ser observada a efetivação da solidariedade.

Destaca-se que a ideia central é a inserção da própria noção de tolerância como fundamento do Direito Internacional dos Refugiados e mesmo de todos os direitos humanos, enxergando-se o ser humano como uma pessoa histórica e concreta, pondo-se o ser humano como fonte de todos os sistemas jurídicos ${ }^{71}$.

O Direito Internacional dos Refugiados deve ser interpretado em consonância com o direito internacional dos direitos humanos, uma vez que a proteção da pessoa humana é devida antes mesmo da condição de refugiado ${ }^{72}$.

Muito se avançou no que tange aos direitos humanos dos refugiados, não obstante diversas denúncias de violações apontam lacunas nos arranjos políticos-administrativos internacionais ou mesmo problemas que devem ser enfrentados pelos países receptores, o que desafia a sinceridade dos valores do país hospedeiro, parecendo meramente uma tolerância condicionada, já que, com estranhamento pelo diferente, ou mesmo mede de perda do mercado de trabalho, gerando uma divisão e um comportamento de não pertencimento por parte da população, provocando indireta e consequentemente, atitudes reprováveis de racismo e xenofobia, em um discurso ideológico entre o bem e o $\mathrm{mal}^{73}$.

${ }_{71}$ PIOVESAN. Flávia Cristina. OLSEN, Ana Carolina Lopes. Tol-
erância e refúgio: Um ensaio a partir do acordo EU-Turquia. Revista
de Direito Internacional, Brasília, v. 14, n. 2, 2017. p. 218.
${ }^{72}$ TRINDADE, Antonio Augusto Cançado. Tratado de Direito In-
ternacional dos Direitos Humanos. Porto Alegre: Sergio Antonio Fabris
Editor, 1997. v. 1. p. 270-271.
${ }^{73}$ PIOVESAN. Flávia Cristina. OLSEN, Ana Carolina Lopes. Tol- 
Não obstante, a tolerância incondicionada pudesse, de mesmo modo, ser prejudicial, por configurar uma forma de dominação ou mesmo indiferença diante da inevitabilidade do convívio, acarreando exclusão social, dado que não promoveria o diálogo ou a compreensão do outro ${ }^{74}$.

Nesse sentido, poder-se-ia cogitar a viabilidade do blockchain como forma de, a partir dos dados pessoais inerentes à pessoa do refugiado, reaproximá-lo de suas origens, não apenas em relação ao espaço, mas em relação a ideologias, política, etnia, religião ou cultura ${ }^{75}$, uma vez que a rede mundial de computadores viabiliza esse extravasamento de fronteiras ao menos de maneira virtual.

Essa reaproximação não deve colidir jamais com a defesa dos direitos humanos, não se admitindo a possibilidade de condicionamento, em prol de uma máxima tolerância para com a figura do outro, não podendo acarretar na violação dos direitos ou devolução diante de entrada irregular, devendo-se direcionar sua interpretação para uma prática de inclusão e respeito como guias mestras, ou guidelines para a aplicação da tecnologia, retirando seu máximo proveito em função de garantir uma melhoria na qualidade da vida humana.

Ainda que haja a aceitação da pessoa do refugiado, muitas vezes este não terá outra opção melhor senão aceitar ceder seus dados biométricos, dentre outros, ainda existindo a hipótese de este modificar sua forma física fenotípica, a qual não é mais reconhecida pela tecnologia de reconhecimento, ou desenvolver problemas em suas retinas, inviabilizando a utilização de todos os outros dados que tenha fornecido, por questão de não haver a certeza de outros meios alternativos de resgate das informações codificadas com base naquele dado.

O objetivo dessas guidelines deve se direcionar essencialmente à atribuição do poder de gerir e garantir a segurança desses dados, estabelecendo critérios exatos de como tais dados são gravados, de que forma são armazenados, no sentido de firmar um verdadeiro sistema de responsabilidade internacional dentro dos Estados que irão se utilizar dos dados fornecidos pelo blockchain,

erância e refúgio: Um ensaio a partir do acordo EU-Turquia. Revista de Direito Internacional, Brasília, v. 14, n. 2, 2017. P. 224-225.

74 SILVA, Sérgio Gomes da. Direitos Humanos: Entre o princípio da igualdade e tolerância. Revista Praia Vermelha, Rio de Janeiro, v. 19, n 1, p.79-94 jan-jun 2010, p.90-91.

75 RORTY, Richard. Contingência, Ironia e Solidariedade. São Paulo: Martins Fontes, 2007. p. 315. ainda que com supervisão da ONU e outros órgãos internacionais.

A responsabilidade é o sistema de justiça que garante a razoabilidade e proporcionalidade de um ordenamento, sistema ou microssistema jurídico, inserindo os Estados subscritores das normas internacionais em uma nova ordem de soberania em que prevalecesse a corresponsabilidade. E, conforme salientado na Conferência de Direitos Humanos de 1993, a verdadeira solidariedade é compartilhar responsabilidades ${ }^{76}$ - Sob essa óptica poderia-se pensar o uso do blockchain, de modo a sempre se pensar nos mecanismos de proteção dos direitos dos refugiados enquanto seres humanos.

\section{Considerações finais}

A tecnologia blockchain, iniciada como um modelo revolucionário não apenas de armazenamento de informações critptografadas e inalteráveis dentro de uma cadeia lógica de informações, foi empiricamente testada em meados do ano de 2017 como parte de um projeto inicial da ONU, como forma de efetivação de seu Plano Mundial de Alimentos, tendo tido aparente êxito sobre a economia, segurança de dados e prevenção de fraudes em campos de refugiados sírios localizados na Jordânia, fugindo dos conflitos ocorridos em sua terra natal.

O entusiasmo sobre o mecanismo de aplicação dessa tecnologia refere-se ao fato de que foi planejada de modo a tornar mais célere transações relacionadas a doações ou à obtenção de alimentos, bem como evitar a corrução ou desvios de finalidades, além de recebida de modo positivo pelos próprios refugiados que muitas vezes forçosamente deslocado sem nenhum planejamento, em decorrência da guerra civil da Síria, tenham deixado seus documentos de identificação pessoal quando da saída do país, inviabilizando os exercícios mais básicos de seus direitos civis.

Utilizando-se essencialmente da biometria, essa tecnologia coleta e utiliza posteriormente dados pessoais com base na própria anatomia humana, como o escaneamento da íris de uma pessoa, em seu direito de per-

\footnotetext{
76 PIOVENSAN, Flávia Cristina. Refugiados sob a perspectiva dos Direitos Humanos: Seminário internacional "Fronteiras em movimento: Deslocamentos e outras dimensões do vivido". Diversitas: Núcleo de Estudos das Diversidades, tolerâncias e conflitos, Universidade de São Paulo, São Paulo, 2013.
} 
sonalidade mais básico que garante sua própria dignidade: seu próprio corpo.

Sem disciplina específica dentro do direito, em um âmbito geral, a tecnologia se desenvolve sem estabelecer parâmetros ou limites em relação ao uso dos dados ou em relação à segurança dos mesmos, ao que pode significar riscos aos direitos dos sujeitos envolvidos, e consequentemente, aos direitos humanos em sua essência de proteção aos vulneráveis, situação agravada em relação aos refugiados, que se encontram em situação de sobreposição de vulnerabilidade ou hipervulnerabilidade.

Nesse sentido, foi alcançado o primeiro objetivo da pesquisa, acerca de realçar os pontos de vantagens e desvantagens práticas do uso da tecnologia para fins de organização de refugiados, ou mesmo, futuramente, para conservação plena de dados que conservem elementos pessoais referentes à preservação de sua ancestralidade antropológica e cultura de origem;

No âmbito do direito internacional, especificamente no caso dos refugiados, a tecnologia blockchain poderá, sem qualquer disciplina, colocar em risco a integridade física ou psíquica da pessoa do refugiado ou mesmo não ter controle da falsidade de dados que podem ser inseridos de modo inadequado e utilizadas com mau vezo pelo ou contra o mesmo. Isso porque a pessoa do refugiado não terá a absoluta certeza de que seus dados serão unicamente utilizados para lhes fornecer alimento ou direitos básicos, não o sendo para lhe rotular de modo discriminatório ou para outros fins contrários aos direitos humanos.

Dados como estado de saúde, vacinas, grau de escolaridade poderão constar do registro do refugiado, fazendo com que, exemplificativamente, em épocas de uma pandemia, tal qual a iniciada em 2020 em relação ao COVID19, o que poderia servir como uma forma de controle abusivo da liberdade, classificação ou estigmatização entre pessoas que migram, fugindo de determinadas guerras ou focos de doenças.

Assim, para os entusiastas do assunto, o uso da tecnologia poderia ajudar tanto aos refugiados quanto às nações anfitriãs. Mas ressalta-se: o uso da tecnologia de maneira inadequada poderá causar muitos danos, motivo pelo qual se deve necessária e urgentemente discutir e disciplinar o uso da tecnologia blockchain para refugiados, dado constituir objetivo a ser alcançado até
2030, sua utilização em massa em outros casos, ao redor do mundo.

Isso porque a lógica dos direitos humanos não poderá ser jamais a mesma lógica aplicada aos usos das tecnologias. As primeiras possuem uma lógica existencial e humanista, e a última uma lógica numérica, cartesiana, de caráter mais utilitário. Ambas essas lógicas não dialogam de maneira a concretizar os direitos humanos. O elemento humanitário sempre deverá prevalecer.

Por fim, em virtude dessa situação, faz-se necessário o estabelecimento de uma estabilidade regulatória, uma padronização no uso dessa tecnologia para um determinado fim, bem como a disciplina e limites ético-jurídicos de seu uso e da gestão dos riscos que podem surgir de seu uso, de maneira de garantir a plenitude da dignidade da pessoa humana, em qualquer hipótese que possa ser utilizada.

Os Estados que escolherem utilizar da tecnologia ou mesmo de dados referentes à ela deverão, mesmo sob supervisão dos órgãos internacionais de defesa dos direitos humanos, garantir a transparência dos critérios e mecanismos de inserção e gestão desses dados, bem como sua responsabilidade, explicando eventuais condutas contraditórias, admitindo a possibilidade de flexibilização da soberania - e jamais sua supressão - para a proteção da pessoa humana de modo universal.

Deve-se sempre ter por escopo a garantia de que, por maior que sejam as promessas de melhorias em relação à vida humana, sempre deve vir conjuntamente o conjunto normativo que garanta a eficácia dos direitos humanos, para que, assim como o avião ou a dinamite, não sejam descobertas que possam ter o seu mau uso, no mau vezo do discurso de proteção do ser humano, o qual deverá ser alinhado com a coerência e o compromisso de proteção dos vulneráveis.

Nesse sentido, alcançou-se o segundo objetivo posto inicialmente, direcionando as necessidades da interpretação do uso dessa tecnologia à luz do Direito Internacional dos Refugiados, formando balizas interpretativas - ou guidelines - para garantir os princípios do humanismo ético que permeia os direitos humanos mais básicos dessas pessoas, sendo necessária uma análise sistemática sobre o Direito Internacional dos Refugiados.

Toda a reflexão sobre a utilização do blockchain hoje tida como uma das tecnologias mais promissoras para o futuro - deverá estar dentro de um sistema se- 
guro e protegido com fortes parâmetros de tolerância dirigida ao sujeito concreto, dentro da sua historicidade, existência, cultura e dignidade, garantindo sua permanência enquanto forem satisfeitos os requisitos de direito, promovendo condições para sua dignidade e construção - ou reconstrução - de seu projeto de vida, após a saída forçada de seu país de origem.

\section{Referências}

ACNUR. Diretrizes sobre os critérios aplicáveis e os padrões relativos à detenção de solicitantes de refúgio, e soluções alternativas à detenção. Genebra: ACNUR, 2012. Disponível em: https://www.refworld.org/cgi-bin/texis/vtx/rwmain/ opendocpdf.pdf?reldoc $=$ y\&docid $=53$ d 602884 . Acesso em: 29 abr. 2021.

BARBOSA, Daniel Cunha. Os mistérios da Dark Web: descubra o que essa rede tem a oferecer e por que pode ser tão perigosa. São Paulo: Eset Brasil, 2019. Disponível em: https://www.welivesecurity.com/br/2019/05/17/ os-misterios-da-dark-web-descubra-o-que-essa-redetem-a-oferecer-e-por-que-pode-ser-tao-perigosa/. Acesso em: 21 abr. 2021

BBC. O que é o jihadismo? News Brasil: BBC, 2014. Disponível em: https://www.bbc.com/portuguese/noticias/2014/12/141211_jihadismo_entenda_cc. Acesso em: 21 abr. 2021.

BECK, Ulrich. Sociedade de risco: rumo a uma outra modernidade. Trad. Sebastião Nascimento. São Paulo: Editora 34, 2011.

ENCYPLOPAEDIA BRITANNICA. Syrian civil war. Britannica, 2020. Disponível em: https://www.britannica.com/event/Syrian-Civil-War. Acesso em: 21 abr. 2021.

CARREAU, Dominique. Droit Internacional. 8 ed. Paris: A. Pedone, 2004.

DECLARAÇÃO UNIVERSAL DOS DIREITOS HUMANOS. Assembleia Geral das Nações Unidas em Paris. 10 dez. 1948. Disponível em: https://nacoesunidas.org/wp-content/uploads/2018/10/DUDH.pdf Acesso em: 21 abr. 2021.

DELL. Underground hacker markets. Secure Words. Round Rock: Dell, 2014.
FIGUEIRA, Rickson Rios. Indigenous refugee and cultural erosion: possibilities and limits of international refugee and indigenous peoples law in the protection of indigenous cultural expression related to traditional land and traditional native languages. Revista de Direito Internacional, Brasília, v. 17, n. 3., p. 439-477, 2020.

GÜNTHER, Hartmut. Pesquisa qualitativa versus pesquisa quantitativa: Esta é a questão? Psicologia: teoria e pesquisa, Brasília: Unb, v. 22, n. 2. maio/ago. 2006.

HÄUSER, Markus. Do robots have rights? The European Parliament addresses artificial intelligence and robotics. Lexology: CMS Germany. Disponível em: https:/ / www.lexology.com/library/detail.aspx?g $=8233438 \mathrm{f}-$ 4ad0-432a-a27e-0018f41468f3. Acesso em: 21 abr. 2021.

HUSSERL, Edmund. A ideia da fenomenologia. Lisboa: Edições 70, 1989.

ID2020. We need to get digital ID right. Disponível em: https://id2020.org/. Acesso em: 15 abr. 2020.

IGREJA, Rebecca Lemos. O Direito como objeto de estudo empírico: o uso de métodos qualitativos no âmbito da pesquisa empírica em Direito. In: MACHADO, Maíra Rocha (org.). Pesquisar empiricamente o Direito. São Paulo: Rede de Estudos Empíricos em Direito, 2017.

IRRERA, Anna. Accenture, Microsoft team up on blockchain-based digital ID network. Technology News: Reuters, 2017. Disponível em: https://www.reuters. $\mathrm{com} /$ article/us-microsoft-accenture-digitalid/accenture-microsoft-team-up-on-blockchain-based-digital-idnetwork-idUSKBN19A22B. Acesso em: 21 abr. 2021.

JI-HYOUNG, Son. Tech disruption plays out in WFP humanitarian initiative. Seul: The Investor, 2019. Disponível em: http://www.theinvestor.co.kr/view. php?ud=20190905000902. Acesso em: 22 abr. 2021.

JUBILUT, Liliana Lyra. O Direito internacional dos refugiados e sua aplicação no orçamento jurídico brasileiro. São Paulo: Método, 2007

JUSKALIAN, Russ. Inside the Jordan refugee camp that runs on blockchain. Massachussets: Mit Technology Review, May/Jun. 2018. Disponível em: https://www. technologyreview.com/s/610806/inside-the-jordanrefugee-camp-that-runs-on-blockchain/. Acesso em: 21 abr. 2021. 
KARAVAS, Vaios; TEUBNER, Gunther. The Horizontal Effect of Fundamental Rights on 'Private Parties' within Autonomous Internet Law. Cambridge: Cambridge Press University, 2002. Disponível em: https://www.cambridge.org/core/services/aop-cambridge-core/content/view/6195520133A79D7A577B9AFCFC383 BB3/S2071832200012153a.pdf/httpwwwcompanynamesuckscom_the_horizontal_effect_of_fundamental_ rights_on_private_parties_within_autonomous_internet_law.pdf. Acesso em: 21 abr. 2021.

LAMOUNIER, Lucas. A história da tecnologia Blockechain: conheça sua Timeline. 101Blockchains, 2018. Disponível em: https://101blockchains.com/pt/historiada-tecnologia-blockchain/. Acesso em: 21 abr. 2021.

MACHADO, Maira Rocha. Estudo de caso na pesquisa em direito. In: MACHADO, Maira Rocha (org.). Pesquisar empiricamente o direito. São Paulo: Rede Empírica de Estudos do Direito, 2017.

MAGRANI, Eduardo. A internet das coisas. Rio de Janeiro: FGV, 2018. Disponível em: https:// bibliotecadigital.fgv.br/dspace/bitstream / handle/10438/23898/A\%20internet $\% 20$ das $\% 20$ coisas.pdf? sequence $=1 \&$ is Allowed $=\mathrm{y}$. Acesso em: 21 abr. 2021.

MAGRANI, Eduardo; SILVA, Priscilla; VIOLA, Rafael. Novas perspectivas sobre ética e responsabilidade de inteligência artificial. In: FRAZÃO, Ana; MULHOLLAND, Caitlin. Inteligência artificial e direito. São Paulo: Revista dos Tribunais, 2019.

MAZZUOLI, Valério de Oliveira. Curso de direito internacional público. 5. ed. São Paulo: Revista dos Tribunais, 2011.

MONT'ALVERNE, Tarin Cristino Frota; MATOS, Ana Caroline Barbosa Pereira. Crônicas de direito internacional público: a política australiana de refúgio e a decisão da suprema corte de Papua Nova Guiné: A ilegalidade do centro de detenção offshore. Revista de Direito Internacional, Brasília, v. 14, n. 3, 2017, p. 2-6

MOORE, Nick. The information Society. In: UNESCO. World information report 1997/1998. Paris: Unesco, 2007.

O’NEAL, Stephen. DLT in Migration Policy: How Blockchain Can Help Both Refugees and Host Nations. Cointelegraph, 2018. Disponível em: https:// cointelegraph.com/news/dlt-in-migration-policyhow-blockchain-can-help-both-refugees-and-host- nations?_ga $=2.157462527 .436306420 .1587005638$ 1708324271.1584115364. Acesso em: 21 abr. 2021.

PIOVESAN, Flávia Cristina. Direitos humanos e o direito constitucional internacional. 14. ed. São Paulo: Saraiva, 2013.

PIOVESAN, Flávia Cristina. O direito de asilo e a proteção internacional dos refugiados. In: ALMEIDA, G. A.; ARAÚJO, N. O direito internacional dos refugiados: uma perspectiva brasileira. Rio de Janeiro: Renovar, 2001.

PIOVENSAN, Flávia Cristina. Refugiados sob a perspectiva dos Direitos Humanos: Seminário internacional "Fronteiras em movimento: Deslocamentos e outras dimensões do vivido". Diversitas: Nucleo de Estudos das Diversidades, tolerâncias e conflitos, Universidade de São Paulo, São Paulo, 2013.

PIOVESAN. Flávia Cristina. OLSEN, Ana Carolina Lopes. Tolerância e refúgio: um ensaio a partir do acordo EU-Turquia. Revista de Direito Internacional, Brasília, v. 14, n.2, 2017, p.215-235.

RAHMAN, Zara. About me now. Blog Zahahanet. Disponível em: https://zararah.net/about/. Acesso em: 21 abr. 2021.

RODOTÀ, Stefano. Dal soggetto alla persona. Napoli: Editoriale Scientífica, 2007.

RODOTÀ, Stefano. Transformações do corpo. Revista Trimestral de Direito Civil. Rio de Janeiro: Padma. v. 5, n. 19, jul/set. 2004.

ROSAS, Eduarda Chacon. Alcance resultados, mas não se esqueça dos propósitos: a dignidade, a ética e os elevados fins. In: MALDONALDO, Viviane Nóbrega; FEIGELSON, Bruno. Advocacia 4.0. São Paulo: Revista dos Tribunais, 2019.

RORTY, Richard. Contingência, Ironia e Solidariedade. São Paulo: Martins Fontes, 2007.

SANTANA, Agatha Gonçalves. Os direitos fundamentais como limite ao poder privado. 2009, 125 f. (Dissertação de mestrado). Belém: UFPa, 2009, p. 12. Disponível em: http://repositorio.ufpa.br/jspui/ bitstream/2011/6750/1/Dissertacao_TutelaDireitosFundamentais.pdf. Acesso em: 22 abr. 2021.

SANTOS, Regina Cândido Lima e Silva; BRASIL, Deilton Ribeiro. O tipo penal brasileiro de promoção de migração ilegal e o princípio da não criminalização da mobilidade humana. Revista de Direito Internacional, Brasília, v.17, n. 2, p. 337, 2020. 
SCHULMAN, Gabriel. www.privacidade-em-temposde-internet.com: $\mathrm{O}$ espaço virtual e os impactos reais à privacidade. In: TEPEDINO, Gustavo; TEIXEIRA, Ana Carolina Brochado; ALMEIDA, Vitor. O Direito Civil entre o sujeito e a pessoa. Belo Horizonte: Fórum, 2016.

SILVA, Sérgio Gomes da. Direitos Humanos: Entre o princípio da igualdade e tolerância. Revista Praia Vermelha, Rio de Janeiro, v. 19, n 1, p.79-94 jan./jun. 2010.

SOUZA, Eduardo Nunes de. Perspectivas de aplicação do abuso de direito às relações existenciais. In: TEPEDINO, Gustavo; TEIXEIRA, Ana Carolina Brochado; ALMEIDA, Vitor. O Direito Civil entre o sujeito e a pessoa. Belo Horizonte: Fórum, 2016.

TAPSCOT'T, Don; TAPSCOT'T, Alex. Blockechain Revolution. São Paulo: SENAI-SP, 2016.

TEIXEIRA, Carla Noura. Por uma nova ordem internacional: uma proposta de constituição mundial. 2009, 306 f. Tese (doutorado). Programa de Pós Graduação em Direito. Pontifícia Universidade Católica de São Paulo, São Paulo, 2009.

THE NATIONAL FUTURE. How blockchain technology has changed the game for Syrian refugees in Jordan. Abu Dhabi, 2019. Disponível em: https://www.thenational.ae/artsculture/how-blockchain-technology-has-changed-thegame-for-syrian-refugees-in-jordan-1.932432. Acesso em: 21 abr. 2021.

UNITED NATIONS. Transforming our world: the 2030 Agenda for Sustainable Development. UN Platform, 2015. Disponível em: https://sustainabledevelopment. un.org/post2015/transformingourworld. Acesso em: 21 abr. 2021. 
Para publicar na Revista de Direito Internacional, acesse o endereço eletrônico www.rdi.uniceub.br ou www.brazilianjournal.org.

Observe as normas de publicação, para facilitar e agilizar o trabalho de edição. 